\title{
In vitro assessment of deleterious impacts of organomodified nanoclays and their incinerated byproducts on human cells
}

\author{
Andrew Philip White \\ West Virginia University, awhite33@mix.wvu.edu
}

Follow this and additional works at: https://researchrepository.wvu.edu/etd

Part of the Toxicology Commons

\footnotetext{
Recommended Citation

White, Andrew Philip, "In vitro assessment of deleterious impacts of organomodified nanoclays and their incinerated byproducts on human cells" (2020). Graduate Theses, Dissertations, and Problem Reports. 7730.

https://researchrepository.wvu.edu/etd/7730

This Thesis is protected by copyright and/or related rights. It has been brought to you by the The Research Repository @ WVU with permission from the rights-holder(s). You are free to use this Thesis in any way that is permitted by the copyright and related rights legislation that applies to your use. For other uses you must obtain permission from the rights-holder(s) directly, unless additional rights are indicated by a Creative Commons license in the record and/ or on the work itself. This Thesis has been accepted for inclusion in WVU Graduate Theses, Dissertations, and Problem Reports collection by an authorized administrator of The Research Repository @ WVU. For more information, please contact researchrepository@mail.wvu.edu.
} 
In vitro assessment of deleterious impacts of organomodified nanoclays and their incinerated byproducts on human cells

\author{
Andrew White \\ Thesis submitted to the Benjamin M. Statler College of Engineering and \\ Mineral Resources at West Virginia University \\ in partial fulfillment of the requirements for the degree of \\ Master of Science in Chemical Engineering \\ Cerasela Zoica Dinu, Ph.D., Committee Chair \\ Rakesh Gupta, Ph.D. \\ Charter Stinespring, Ph.D. \\ Todd Stueckle, Ph.D.
}

Department of Chemical and Biomedical Engineering

Morgantown, West Virginia

2020

Keywords: Organomodified nanoclays, Electric cell impedance sensing, High content screening, Cell monolayer, High-throughput real-time, Pulmonary inflammation

Copyright 2020 Andrew White 


\title{
Abstract
}

\author{
Andrew White
}

Organomodified nanoclays (ONCs; i.e., smectite clays with different organic coatings), act as nanofillers in applications ranging from automotive, to aerospace, and biomedical implementations. Because of their large utilization, ONC industry is projected to be a U.S. \$3.3 billion industry by 2023. However, emerging studies showed that ONCs and ONCnanocomposites could harbor health risks upon pulmonary exposure and along their life cycle, namely during synthesis, handling, use, manipulation, and disposal. Specifically, the potential for exposure and adverse effects on human health primarily includes release of dry particulate during handling, manipulation, release during use, and release during end-of-life disposal or recycling scenarios. Compared to other ENMs, however, little information exists describing which physicochemical properties contribute to their health risk.

My M.S. work at West Virginia University in Prof. Dinu's group aimed to evaluate acute toxicity of a library of ONCs prior to and after simulated disposal by incineration. The analysis conducted high content screening and real-time electric cell impedance sensing on bronchial epithelial cell monolayers for coupled high-throughput in vitro assessment strategies aimed to evaluate acute toxicity of a library of ONCs prior to and after simulated disposal by incineration. Coating-, incineration status-, and time-dependent effects were considered to determine changes in the pulmonary airway epithelial monolayer integrity, cell transepithelial resistance, apoptosis, and cell metabolism respectively.

Results showed that after exposure to each particle at its $\mathrm{IC}_{50}$, pristine nanoclay displayed acute loss of monolayer coverage, resistance, and metabolism, coupled with increased number of apoptotic cells. Conversely, three different ONCs of prevalent use displayed little loss of monolayer integrity but exhibited differential coating-dependent increased apoptosis and up to 40$45 \%$ initial reduction in cell metabolism. Moreover, incinerated byproducts of ONCs exhibited significant loss of monolayer coverage and integrity, increased necrosis, and little evidence of monolayer re-establishment.

These findings indicate that characteristics of organic coating type largely determine mechanism of cytotoxicity and the ability of the monolayer to recover. Use of high content screening, coupled with traditional in vitro assays prove to serve as a rapid pulmonary toxicity assessment tool to thus help define prevention by targeted physicochemical material properties design strategies.

The above contributions to understanding deleterious effect of nanomaterials on human model systems is meritorious and transformative and allows for creating new tools for toxicological pathways assessment to be considered for improved prevention by design strategies and enhanced safety practices. 
The above contributions has been included in a co-first author publication, namely: Stueckle, T.*, White, A.*, Wagner, A., Gupta, R., Rojanasakul, Y., Dinu, C.Z., "Impacts of Organomodified Nanoclays and their Incinerated Byproducts on Bronchial Cell Monolayer Integrity", Chemical Research in Toxicology (2019) 32, 12, 2445-2458 (*Authors contributed equally). 


\section{Acknowledgements:}

First, I would like to express my deepest gratitude for Dr. Cerasela Dinu's support and guidance throughout this project and my studies at WVU. Her patience, tirelessness, enthusiasm, and vast knowledge have been invaluable and inspiring. Additionally, I would like to appreciate the opportunities, insights, and assistance which Dr. Todd Stueckle have provided throughout my studies and this project. Also, the support, resources, and guidance from my committee members, Drs. Rakesh Gupta and Charter Stinespring, have been instrumental in shaping this project and my academic pursuits.

I would like to recognize the invaluable assistance and advice my lab members have provided throughout my work at WVU. Furthermore, I would like to acknowledge the collaborative efforts of other faculty and lab groups who have contributed to this project: Dr. Yon Rojanasakul and his group for the space I've been so graciously allowed to share, Dr. Rakesh Gupta and Dr. Sushant Agarwal for sharing materials and providing guidance, WVU Shared Research Facilities and faculty for their tireless efforts and shared space, and Drs. Sierros and Sabolsky and their respective lab groups for sharing their instrumentation and valuable time. This project has required numerous collaborative efforts. Many individuals at both WVU and NIOSH have selflessly given me their time, advice, resources, and so much more.

Moreover, I would like to thank my advisors and peers from the WVU IGERT program. This program has been instrumental in shaping my education and career. Furthermore, I would like to thank the faculty of and my peers within the WVE CBE department for their continued guidance and support as well as for their tireless efforts in building such a wonderful environment of educational and academic pursuit. 
Finally, my deep and sincere gratitude to my family for their continuous and unparalleled love, help, and support. I am forever indebted to my parents, William and Ellen, for their part in my education and perseverance to provide me with the best of opportunities as well as to my wife, Molly, for always having faith in my abilities and supporting me so lovingly.

Financial support for this work was through the National Institutes of Health (R01ES022968), NIOSH Nanotechnology Research Center 921043S, and IGERT program at West Virginia University (WVU). I also acknowledge use of WVU Shared Research Facilities and the WVU Flow Cytometry Core Facility (supported by the NIH equipment grant number S10OD016165 and the Institutional Development Award (IDeA) from the National Institute of General Medical Sciences of the NIH under grant numbers P30GM103488 (CoBRE) and P20GM103434 (INBRE)). 


\section{Table of contents:}

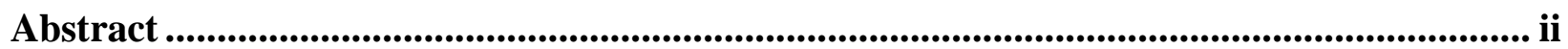

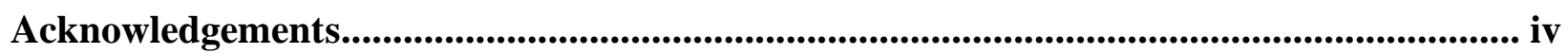

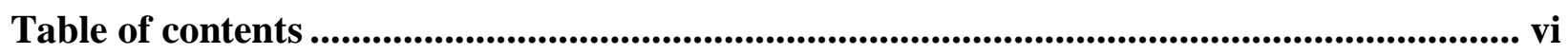

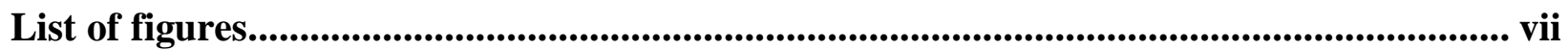

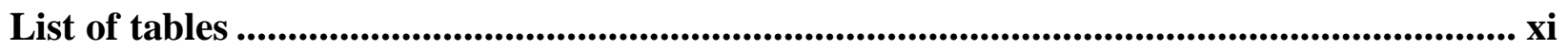

List of acronyms................................................................................................................................. xii

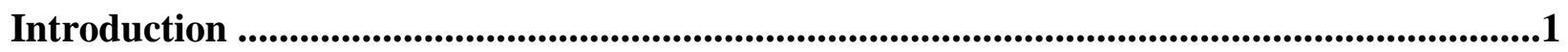

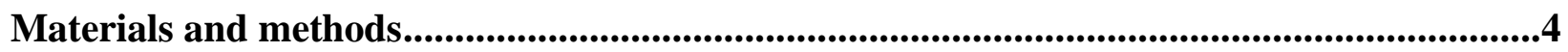

Statistical analysis .........................................................................................................................11

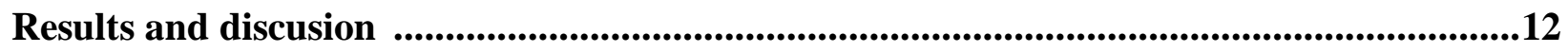

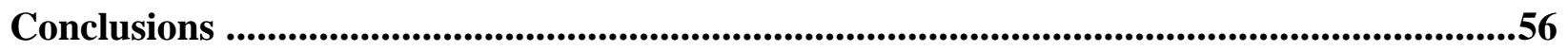

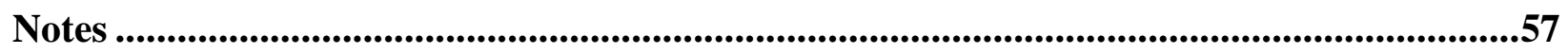

References ........................................................................................................................................58

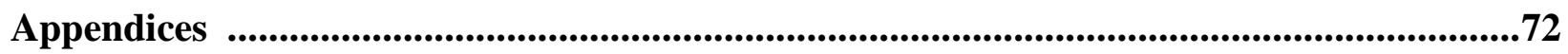




\section{List of figures:}

Figure 1: Surface coating chemistry of three Nanomer organomodified nanoclays (ONCs). Chemical structures of surface coatings on montmorillonite nanoclay.

Figure 2: Surface coating chemistry of three Nanomer organomodified nanoclays (ONCs). Surface chemistry determination of a) as-produced nanoclay, and b) incinerated byproduct by Fourier Transform Infrared Spectroscopy (FTIR) analysis.

Figure 3: Elemental surface analysis of as received nanoclay as determined by energy dispersive analysis (EDX). Mean area under the curve from EDS spectra were calculated and compared. Inset depicts trace element $\%$ weight. $*$ and $\sim$ indicate significant differences compared to PGV and as-produced counterpart, respectively $(\mathrm{p} \leq 0.05)$.

Figure 4: Elemental surface analysis of incinerated byproduct of pristine nanoclay as determined by energy dispersive analysis (EDX). Mean area under the curve from EDS spectra were calculated and compared. Inset depicts trace element $\%$ weight. $*$ and $\sim$ indicate significant differences compared to PGV and as-produced counterpart, respectively $(\mathrm{p} \leq 0.05)$.

Figure 5: Hydrodynamic diameter of as-produced Nanomer nanoclays in PBS vs. DMEM medium. * indicates a significant difference compared to PBS $\left(\mathrm{p} \leq 0.05 ; 90^{\text {th }}\right.$ percentile of particles analyzed). 
Figure 6: Representative 10x magnification images from $\mathrm{HCS}$ of Nanomer organomodified nanoclay and incinerated byproduct particle exposure to human bronchial epithelial cells monolayer integrity, cell shape, and nuclear morphology. Cell membrane (red) and cytoplasm (green) fluorescent probes were imaged in separate assays with nuclear (blue) probe. White arrows indicate cell morphology change from unexposed cuboidal-shaped cells to PGVexposed elongated cell morphology.

Figure 7: Quantification of HCS analysis of bronchial epithelial monolayer coverage to Nanomer organomodified nanoclay and incinerated byproduct exposure.

Figure 8: Quantification of HCS analysis of bronchial epithelial monolayer cell count to Nanomer organomodified nanoclay and incinerated byproduct exposure.

Figure 9: Single cell area of bronchial epithelial cells exposed to pre- and post-incinerated nanoclays. No significant difference was observed.

Figure 10: Quantification of HCS analysis of bronchial epithelial monolayer nuclear area to Nanomer organomodified nanoclay and incinerated byproduct exposure.

Figure 11: Quantification of HCS analysis of bronchial epithelial monolayer nuclear intensity to Nanomer organomodified nanoclay and incinerated byproduct exposure. 
Figure 12: Representative measurements of normalized resistance upon exposure for $48 \mathrm{~h}$ to (a) nanoclays and (b) byproducts.

Figure 13: Representative measurements of normalized $\alpha$ parameter after $48 \mathrm{~h}$ of exposure is shown for (a) nanoclays and (b) byproducts $(n=4)$. Horizontal dashed lines indicate start of particle exposure.

Figure 14: Flow cytometric analysis of the effect of treatment on cell apoptosis and necrosis. Representative flow cytometry scatter plots.

Figure 15: PGV/I31 particle-only control samples for apoptosis flow cytometry analysis.

Figure 16: I34/I44 particle-only control samples for apoptosis flow cytometry analysis.

Figure 17: PGV/I31900 particle-only control samples for apoptosis flow cytometry analysis.

Figure 18: I34900/I44900 particle-only control samples for apoptosis flow cytometry analysis.

Figure 19: Flow cytometric analysis of the effect of treatment on cell apoptosis and necrosis. Quantitative comparison of live, apoptotic, and necrotic cells. * indicates significant 
difference between exposed samples and controls; indicates significant difference between nanoclays and the corresponding thermally degraded byproduct $(\mathrm{p}<0.05)$.

Figure 20: Cellular viability determined with WST-1 assay after 24, 48, and $72 \mathrm{~h}$ exposure, respectively to nanoclays.

Figure 21: Cellular viability determined with WST-1 assay after 24, 48, and $72 \mathrm{~h}$ exposure, respectively to byproducts. 


\section{List of tables:}

Table 1. Hydrodynamic diameter distributions of suspended as-produced and incinerated byproduct of pristine nanoclay and ONCs in BEAS-2B culture medium and PBS. Values represent mean and $\mathrm{SE}(\mathrm{n}=3)$. 


\section{List of acronyms:}

- ATTC: American Type Culture Collection

- ANOVA: Analysis of variance

- BCA: Bicinchoninnic acid assay

- BSA: Bovine serum albumin

- DMEM: Dulbacco minimum essential media

- DLS: Dynamic light scattering device

- ECIS: Electrical cell impedance sensing

- EDX: Energy dispersive X-ray spectroscopy

- EDTA: Ethylene diaminetetracetic acid

- FBS: Fetal bovine serum

- FACS: Fluorescence assisted cell sorting

- FSC: Forward scatter

- FTIR: Fourier Transform Infrared Spectroscopy

- BEAS-2B: Immortalized human lung epithelial cells

- OSHA: Occupational Safety and Health Administration

- PBS: Phosphate Buffer Saline

- PI: Propidium iodide

- SEM: Scanning Electron Microscopy

- SSC: Side scatter

- WST-1: Water soluble tetrazolium 


\section{Introduction:}

Advanced and additive manufacturing strategies that produce nanocomposite are quickly emerging from research and development into larger scale implementation for numerous industrial, commercial, and healthcare sectors. Reports show that thermoplastic and thermoset nanocomposites for instance are rapidly growing at $25 \%$ annually and because of their proven sustainable and low-cost production, they are poised to replace older and more costly technologies. ${ }^{1}$

Nanocomposites use one or several engineered nanomaterials (ENMs) incorporated within their matrix to gain such additional technological advantages. One of the largest ENM classes by volume $(70 \%)$ and one of the cheapest on a per mass basis ${ }^{2}$ for use in nanocomposites fabrication are organomodified nanoclays (ONCs), smectite clays coated with organic modifiers. Because of their large implementation, ONC industry is projected to be a U.S. $\$ 3.3$ billion industry by $2023 .{ }^{3}$ However, emerging studies showed that ONCs and ONC-nanocomposites could harbor health risks upon pulmonary exposure and along their life cycle. ${ }^{4-6}$ Specifically, the potential for exposure and adverse effects on human health primarily includes release of dry particulate during handling, manipulation, release during use, ${ }^{5,7}$ and release during end-of-life disposal or recycling scenarios. ${ }^{8,}$ ${ }^{9}$ Two studies from China for instance already reported high airborne concentrations with resulting genotoxicity markers in collected blood from workers. ${ }^{10,11}$ It is projected that a majority of end-

of-life scenarios for nanocomposites known to include municipal incineration and recycling ${ }^{12-14}$ are also to lead to similar deleterious health effects. Although less is known about such end-of-life release and exposure routes, several controlled studies have appeared to confirm release of airborne particulate during ONC nanocomposite shredding activities for recycling, with silica dust 
making up the largest proportion of incinerated fly ash. ${ }^{12,15}$ Moreover, other recent studies reported that fly ash from incinerated nanocomposite can harbor unique toxicities not present in preincinerated forms. ${ }^{16-18}$ In one of such studies it was reported the first dose- and time-dependent pulmonary effects assessment of pre- and post-incinerated Cloisite 30B, a quaternary ammonium compound coated nanoclay, to pristine montmorillonite (Cloisite $\mathrm{Na}$ ) known to induce silicosislike disease in Fuller' s Earth miners. ${ }^{19}$ Results showed that Cloisite 30B induced mild lung airway damage with a delayed low grade, but persistent inflammatory response in aspirated mice, which was overshadowed by a robust, pro-inflammatory response following Cloisite Na exposure. In addition, it was shown that incinerated Cloisite $\mathrm{Na}$ with an amorphous pyrogenic silica morphology caused an acute, but transient, inflammatory response while incinerated Cloisite 30B, with a more crystalline morphology, produced a low-grade chronic inflammation, similar to crystalline silica. ${ }^{20}$ Considering that at present, inorganic mineral dust inhalation in occupational settings accounts for $15.4 \%$ of asthma and 1.8 million COPD cases totaling a combined U.S. \$6.23 billion $^{21}$ and considering that manufacturing sector jobs contribute to $43.8 \%$ of silicosis deaths, ${ }^{22}$ there is a pressing need to establish high screening content strategies that allow for health risks assessment along ONCs life cycle.

The present study aims to establish a high-throughput screening strategy to evaluate potential differences in mode of action of selected ONCs of prevalent use and their incinerated byproducts on a confluent monolayer of human bronchial epithelial cells, a model for human pulmonary airway. To demonstrate study's feasibility, we hypothesized that presence of hydroxyl groups in the ONCs would drive a robust and different mode of cytotoxic action on the selected cells when compared to pristine montmorillonite and incinerated byproducts, with known surface 
available silica groups. Using high content screening, electrical cell impedance sensing (ECIS), and flow cytometry, combined with traditional cell metabolism screening, we foresee the ability to inform and improve 'prevention-by-design' strategies to protect workers and general public while retaining the benefits of ONC nanocomposite technology. The generated results are expected to further our understanding of how physical and chemical properties of ONCs along their life cycle influence modes of toxic action to human airways, with future investigations in both pulmonary in vivo animal models and human workers to be tailored to identify specific adverse health effects to thus help protect against ONC-induced pulmonary disease. 


\section{Materials and methods:}

\section{Nanoclay and byproduct sample information}

Nanoclay samples (i.e., unmodified, bentonite (Nanomer® PGV) and surface modified

clays: Nanomer® I.31PS $\quad(0.5-5 \quad$ wt. $\%$ aminopropyltriethoxysilane and $15-35$ wt.\% octadecylamine), I.34TCN (25-30 wt.\% methyl dihydroxyl hydrogenated tallow ammonium), and I.44P (35-45 wt.\% dimethyl dialkyl amine); Figure 1) were purchased from Sigma-Aldrich. Thermal degradation by incineration of such nanoclays was performed at $900{ }^{\circ} \mathrm{C}$ using a TGA701 Thermogravimetric Analyzer (LECO). Resultant ash was collected and used as a model for thermally degraded byproduct formation (referred to hereafter as PGV900, I31900, I34900, and I44900, respectively)..$^{23,24}$

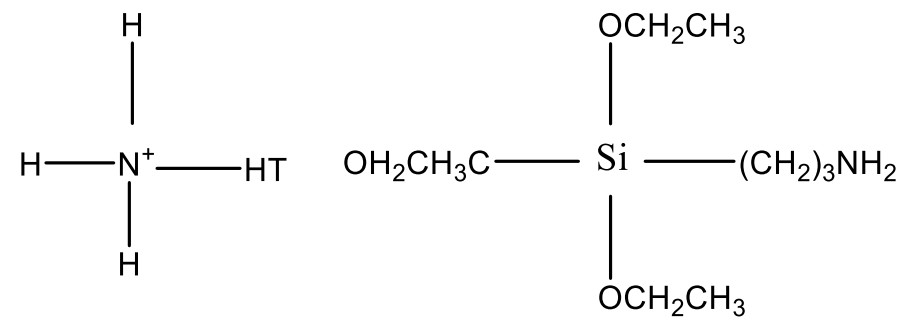

13
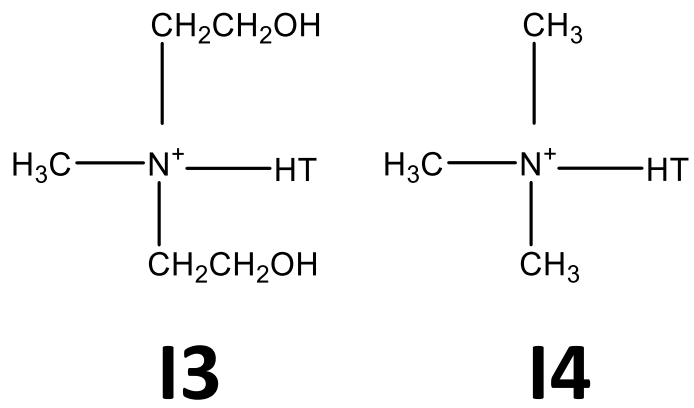

Figure 1. Surface coating chemistry of three Nanomer organomodified nanoclays (ONCs). Chemical structures of surface coatings on montmorillonite nanoclay. 


\section{Nanoclay and byproducts characterization}

Chemical composition of each nanoclay or resulting byproduct (i.e., nanoclays PGV, I.31PS, I.34TCN, I.44P and byproducts PGV900, I31900, I34900, and I44900, respectively) was determined by Fourier Transform Infrared Spectroscopy (FTIR) using a Digilab FTS 7000 equipped with a diamond Attenuated Total Reflection (ATR; Varian). Scans were executed at a

resolution of $4 \mathrm{~cm}^{-1}$ and in a range of $4000-400 \mathrm{~cm}^{-1} ; 100$ scans were merged and averaged to obtain a full spectrum.

Elemental composition of the individual samples (i.e., nanoclays and byproducts) was evaluated via energy dispersive X-ray spectroscopy (EDS) on a Hitachi S-4700 Field Emission Scanning Electron Microscope (Hitachi High-Technologies Corporation) operating at $20 \mathrm{kV}$. Samples were fixed to carbon tape prior to analysis.

Nanoclays or byproducts size distributions was investigated in phosphate buffered saline (PBS; Lonza) and Dulbecco's modified Eagle medium (DMEM; Corning) supplemented with 5\% fetal bovine serum (FBS; Life Technologies) using dynamic light scattering (DLS) and a Mastersizer 2000 equipped with a Hydro 2000S accessory (Malvern Instruments). For sch analysis, solutions of each sample were bath sonicated and added to the Hydro 2000S until laser obscuration was within 10-20\%. Measurements were performed at a constant stirring speed of $1750 \mathrm{rpm}$ and under constant sonication, with results being presented as the average of 3 consecutive repetitions. 


\section{Cell culture and treatment}

Low passage immortalized human bronchial epithelial cells (BEAS-2B; ATCC) were cultured in DMEM supplemented with 5\% FBS, 1\% L-glutamine (Corning), and $1 \%$ penicillin/streptomycin (Life Technologies). Cell cultures were maintained in $100 \mathrm{~mm}$ dishes (Corning) and kept in a humidified atmosphere of $37{ }^{\circ} \mathrm{C}$ and $5 \% \mathrm{CO}_{2}$. Regular passaging of cells was performed using $0.25 \%$ trypsin/ethylene diamine tetraacetic acid (EDTA) solution (Life Technologies).

Half-maximal inhibitory concentration $\left(\mathrm{IC}_{50}\right)$ values for each nanoclay and its byproduct were determined using BEAS-2B cells seeded at a density of $1.5 \mathrm{E}+05$ cells $/ \mathrm{ml}$ into 12 well plates (Thermo Scientific) and following established protocols ${ }^{1}$. Briefly, confluent cells were exposed to nanoclays or byproducts previously bath sonicated for $10 \mathrm{~min}(2510$ Branson: $100 \mathrm{~W})$ in dispersant DMEM supplemented with 5\% FBS. The treatment was performed at doses of $0,0.03,0.3,13,26$, 66,132 , and $197 \mu \mathrm{g} / \mathrm{cm}^{2}(0-750 \mu \mathrm{g} / \mathrm{ml})$ for $24 \mathrm{~h}$. Following exposure, cells were harvested and stained with $0.4 \%$ trypan blue solution (Invitrogen). Live cell counts were performed on a Countess automated counter (Invitrogen) to determine $\mathrm{IC}_{50}$ values to be used in the remaining cellular assays.

\section{High-content cell imaging}

Cells were seeded into black 96-well high-content screening (HCS) plates (Corning) at a density of $1.5 \mathrm{E}+05$ cells $/ \mathrm{ml}$ and allowed to proliferate and achieve a confluent monolayer for 24

$\mathrm{h}$. The cells were subsequently exposed to the $\mathrm{IC}_{50}$ values of each nanoclay or byproduct for $24 \mathrm{~h}$. Following exposure, cells were carefully washed with PBS and stained with $1 \mu \mathrm{l} / \mathrm{ml}$ Hoechst 33342 
(Thermo Fisher Scientific) and $1 \mathrm{mM}$ CellMask ${ }^{\circledR}$ Red (Thermo Fisher Scientific) for $30 \mathrm{~min}$ at 37 ${ }^{\circ} \mathrm{C}$ to evaluate and compare monolayer integrity at the different exposure doses.

Stained samples were once again washed with PBS and imaged using the ImageXpress Micro XLS Widefield High-Content Analysis System (Molecular Devices) under 10 and 20X objectives. For this, the population(s) of cells were analyzed by scanning through the bottom of the plate and acquiring images for each desired fluorescence channel (i.e., chosen to accommodate the above listed staining). Briefly, the blue channel (excitation /emission of 377/447 nm) was used to visualize Hoechst, while the Cy5 (excitation /emission of 628/692 nm) channel was used to visualize CellMask. The experiment was conducted as 3 independent runs with 8 wells per nanoclay or byproduct sample being tested. For each well, 4 independent fields (image size of $1400 \times 1400 \mu \mathrm{m})$ were sampled.

Accompanying MetaXpress Software v.5.3 was used to analyze each image with the multiwavelenth cell scoring module. Briefly, stained area and mean fluorescence intensity were exported for each cellular event and used to define and analyze cell number, individual cell area, monolayer coverage (\% of stained area with respect to image size), and nuclear distribution (as a function of nuclear area and intensity), respectively. For this, cells were defined as nuclear (Hoechst positive) events with minimum and maximum widths of 5 and $30 \mu \mathrm{m}$ respectively, as well as an intensity above local background of 300 gray levels. The module allowed for quantification of single cell parameters including stained area and intensity. Number of Hoechst stained nuclei was subsequently used to define cell count while mean region of interest (ROI) of Hoechst 33342 was used to define nuclear size. Lastly, single cell area was defined using the ROI 
of both wavelengths and monolayer coverage was calculated as the percentage of stained area with respect to image size.

As a supplementary/ complementary analysis to the Hoechst/CellMask stain, the assay was repeated by substituting a cytoplasmic stain for the membrane stain. The same exposure conditions and materials were used. Following exposure, cells were carefully washed with PBS and stained with $1 \mu \mathrm{l} / \mathrm{ml}$ Hoechst 33342 and $5 \mu \mathrm{M}$ Calcein AM (Thermo Fisher Scientific) for 20 min at 37 ${ }^{\circ} \mathrm{C}$. Stained samples were again washed with PBS and imaged with a FITC filter (excitation / emission of $470 / 525 \mathrm{~nm}$ ) on the ImageXpress system; the same method of image analysis was applied. Stained particle-only were used as controls and analyzed as indicated above to determine any nanoparticle-dye interactions; analysis was performed for both assays.

\section{Electrical cell-substrate impedance sensing (ECIS)}

Assessment of cellular behavior was performed in real time with an electrical cell impedance instrument (ECIS-Z $\theta$; Applied BioPhysics). For each experiment, a pre-fabricated ECIS array (96W20idf) of 96 wells (each well containing an electrode), with a total sensing area of $3.985 \mathrm{~mm}^{2}$ was used. Measurements were performed at a frequency of $4000 \mathrm{~Hz}$. Prior to every cellular experiment, the electrodes were stabilized (i.e., to minimize electrode drift) and preequilibrated with $200 \mu \mathrm{l}$ of DMEM for $2 \mathrm{~h}$. After electrode stabilization, BEAS-2B cells were seeded into the array at a density of $1.5 \mathrm{E}+05$ cells/ml (22,500 cells/well) in $150 \mu \mathrm{l}$ of media/well.

Cell cultures were allowed to form a confluent monolayer for $24 \mathrm{~h}$, as determined by a constant resistance instrument reading. After this period, they were exposed to the $\mathrm{IC}_{50}$ values of 
the nanoclays or byproducts (identified as listed above) and monitored continuously for $48 \mathrm{~h}$. Specifically, a multi-frequency module was used to monitor the alpha parameter, or the resistance

due to current passing between the electrode and basal cell membrane $e^{24-26}$ and known to be a sensitive indicator of cellular adhesion and cell-substrate interactions. ${ }^{27,28}$

\section{Apoptosis/necrosis detection}

The percentages of apoptotic and necrotic cells were determined using a TACS Annexin V-FITC apoptosis detection kit (Trevigen). For this, BEAS-2B cells were seeded into 12-well plates at $2.5 \mathrm{E}+05$ cells/well for $24 \mathrm{~h}$. Cells were then exposed to the $\mathrm{IC}_{50}$ values of the nanoclays or byproducts for $24 \mathrm{~h}$, harvested, and centrifuged at $300 \mathrm{~g}$ for $8 \mathrm{~min}$ at $4{ }^{\circ} \mathrm{C}$. Each sample was then incubated with $1 \mu \mathrm{l}$ Annexin V-FITC and $10 \mu \mathrm{l}$ propidium iodide (PI) prepared in ice-cold $1 \mathrm{X}$ binding buffer in the dark at room temperature for $15 \mathrm{~min}$ (all reagents were purchased from Invitrogen). Samples were subsequently suspended in $400 \mu \mathrm{l}$ binding buffer and analyzed via flow cytometry (LSR Fortessa; BD Biosciences).

FACS excitation of $488 \mathrm{~nm}$ and emission wavelengths of $530 \mathrm{~nm}$ (FITC fluorescence) and $610 \mathrm{~nm}$ (PI fluorescence), respectively were considered. Approximately 10,000 events were recorded for each sample and scored for percentages of viable (FITC -, PI -), early apoptotic $($ FITC +, PI -), apoptotic $($ FITC +, PI +), and necrotic (FITC -, PI +) cells, respectively. Analysis was performed using FCS Express 6 software (De Novo Software); double labeling required compensation using cells stained solely with each dye. Additionally, particle-only controls (i.e., nanoclay or byproduct suspended in media) stained with each dye were also analyzed to determine any nanoparticle-dye interactions. 


\section{Cellular metabolic activity}

Evaluation of mitochondrial metabolic activity upon nanoclay or byproduct exposure was performed using a water-soluble tetrazolium salt (WST-1) assay (TaKaRa Bio). For this, cells were seeded into 96-well plates (CELLTREAT Scientific Products) at a density of 1.5 E+05 cells/ml. After $24 \mathrm{~h}$, the cells were treated with the $\mathrm{IC}_{50}$ value of each nanoclay or byproduct (identified previously); cells in media served as controls.

Changes in cellular viability were detected as a colorimetric shift resulting from reduction of the tetrazolium salt (4-[3-(4-idophenyl)-2-(4-nitrophenyl)-2H-5-tetrazolio]-1,3-benzene disulfonate) into formazan, ${ }^{29}$ with the colorimetric change being known to be directly proportional to the quantity of metabolically active cells. ${ }^{30}$ Following 24,48 , or $72 \mathrm{~h}$ of exposure, $10 \mu \mathrm{l}$ of WST1 reagent was added to each well. The cells were incubated for an additional $2 \mathrm{~h}$ at $37{ }^{\circ} \mathrm{C}$. Changes in sample absorbance were evaluated using a FLUOstar OPTIMA plate reader (BMG LABTECH) at $485 \mathrm{~nm}$. Media and nanoclay or byproduct suspended in media served as blanks with obtained absorbance measurements from these blanks being deducted from their corresponding cellular measurement(s). 


\section{Statistical analyses:}

In addition to the statistical analysis as specified above, each cellular assay was repeated in technical triplicates and biological duplicates $(\mathrm{n}=6)$. ECIS was repeated 4 times with biological replicates of 4 for each sample $(n=16)$. All values are presented as the mean value for the indicated replicates with (+/-) SE bars. Significance was evaluated with a one-way analysis of variance (ANOVA) and the Tukey-Kramer method with JMP 13.0 software (SAS Institute). Results were considered significant when ${ }^{*} \mathrm{p}<0.05$. 


\section{Results and discussion:}

There is a critical need to assess organically modified nanoclays (ONCs) prior to manufacturing, production, use, and disposal in order to design viable strategies that mitigate both user and environmental risks associated with such materials implementation. ${ }^{31}$ The need is driven by large scale integration of ONCs into both consumer and industrial applications. ${ }^{3}$ This study aimed to determine changes in cellular behavior upon exposure to ONCs and pristine nanoclays, all using high-content screening (HCS) and high-throughput real-time electric cell impedance sensing (ECIS) to thus overcome limited metrics and large time scale variations provided by the standard single point cell-based assays such as water-soluble tetrazolium salt (WST-1). By analyzing a large number of cells in complex environments (i.e., upon exposure to pristine nanoclay and ONCs that mimic user-manufacturing or their byproducts that mimic disposal by incineration) and by providing numerical representation to characterize cellular behavior, we envision the ability to develop a systematic assessment strategy of large applicability and implementation capability to other kind of nanomaterials or their downstream byproducts, all along their lifecycle.

The model systems used for the proposed assessment were selected based on their level of implementation in manufacturing and consumer settings respectively. Namely, Nanomer® clay PGV, pristine bentonite, as well as Nanomer® clays I31, I34, and I44, organically modified bentonites (Figure 1) have been frequently incorporated into polymer matrices ${ }^{32-36}$ and served as test materials to model human inhalation exposure during manufacturing, production and use. Thermally degraded byproducts of these samples (i.e., PGV900, I31900, I34900, and I44900) served as test materials to model the exposure in a disposal environment by incineration. An 
immortalized human bronchial epithelial cell line (BEAS-2B) was used for high-throughput cell-

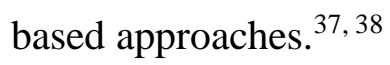

\section{Physicochemical characterization of nanoclays and byproducts}

Presence of an organic modifier has previously been shown to influence toxicity of nanoclays. For instance, Stueckle et al., found that hydrophobic organo-modification resulted in reduced pulmonary toxicity and delayed inflammatory response in mouse lung compared to exposure to pristine, uncoated nanoclay. ${ }^{20}$ Complementary, we previously showed that physicochemical properties such as size, morphology, agglomeration, and surface chemistry of the above selected nanoclays or byproducts alter behavior of such materials in a biological environment as well as dictate their potential to induce cellular stress and changes. ${ }^{39,40}$

Herein we briefly confirmed previous physicochemical characterization by evaluating pristine nanoclay and ONCs as well as their byproducts. Specifically, with Fourier Transform Infrared Spectroscopy (FTIR) analysis of the as-received clays (Figure 2a) we confirmed the presence of the organic modifiers in all the ONCs, with peaks associated with $\mathrm{Si}-\mathrm{O}-\mathrm{Si}\left(1000 \mathrm{~cm}^{-}\right.$ $\left.{ }^{1}\right)$ and $\mathrm{Al}-\mathrm{OH}-\mathrm{Al}\left(900 \mathrm{~cm}^{-1}\right)$ being identified. We also confirmed that thermal degradation induced loss of the peaks of the organo-modifiers as well as a shift in peaks associated with $\mathrm{Si}-\mathrm{O}-\mathrm{Si}$ and Al-OH-Al (Figure 2b) indicating the loss of both the organo-modifier and the aluminosilicate lattice structure. 

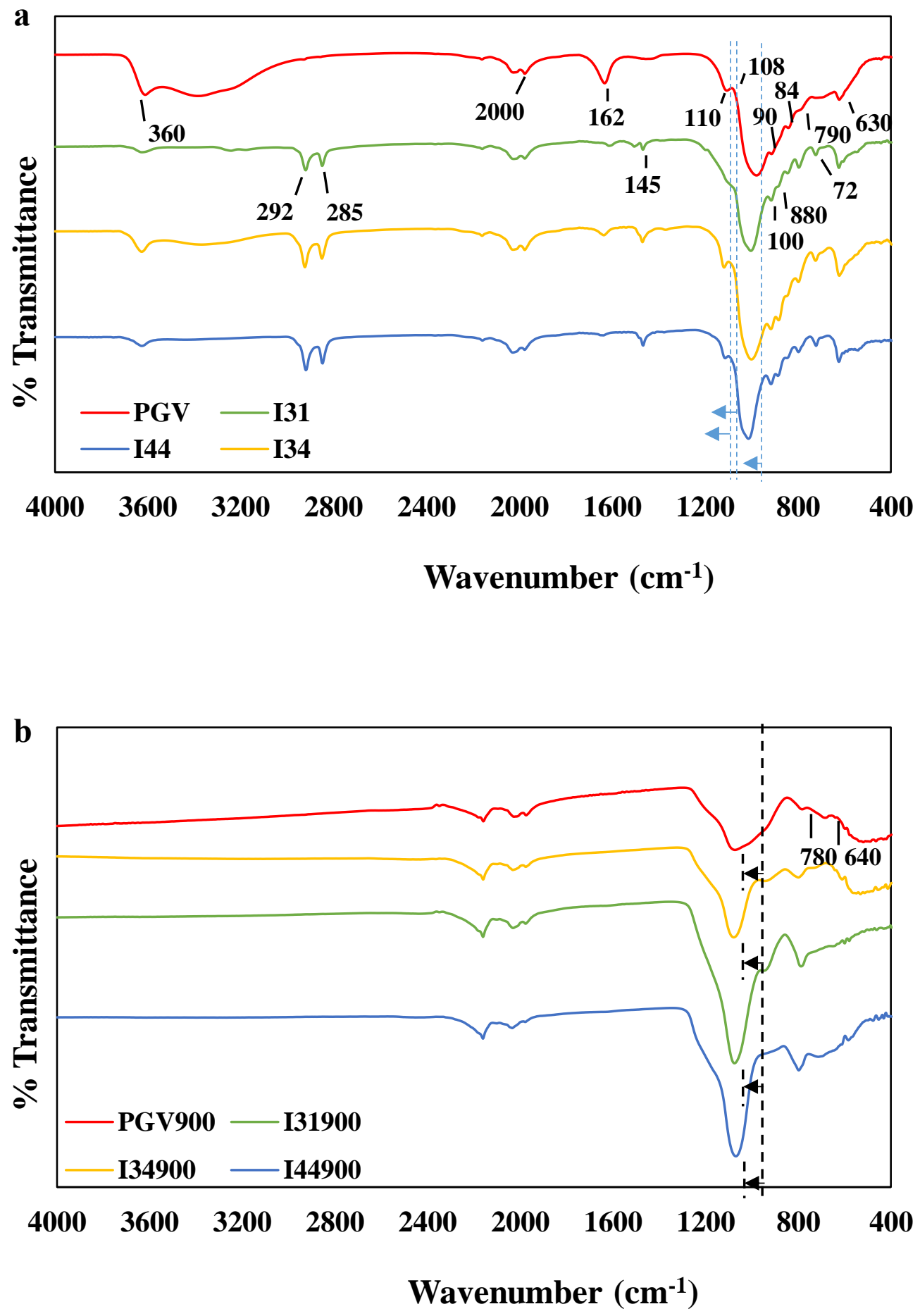

Figure 2. Surface coating chemistry of three Nanomer organomodified nanoclays (ONCs). Surface chemistry determination of a) as-produced nanoclay and b) incinerated byproduct by Fourier Transform Infrared Spectroscopy (FTIR) analysis. 
Analysis of the elemental composition of as-received samples (Figure 3) revealed that ONCs had higher amounts of C relative to PGV pristine nanoclay. Additionally, I31 and I44 had higher amounts of $\mathrm{O}$ and lower amounts of $\mathrm{Al}, \mathrm{Si}$, and $\mathrm{Fe}$ relative to $\mathrm{PGV}$. These differences in composition further confirmed previous report and the presence of the organo-modifiers in I31, I34, and $\mathrm{I} 44 .{ }^{23}$ Thermal degradation caused a decrease in $\mathrm{C}$ content and increase in $\mathrm{O}, \mathrm{Al}$, and $\mathrm{Si}$, thus confirming loss of both the organic modifiers and aluminosilicate lattice structure (Figure 4).

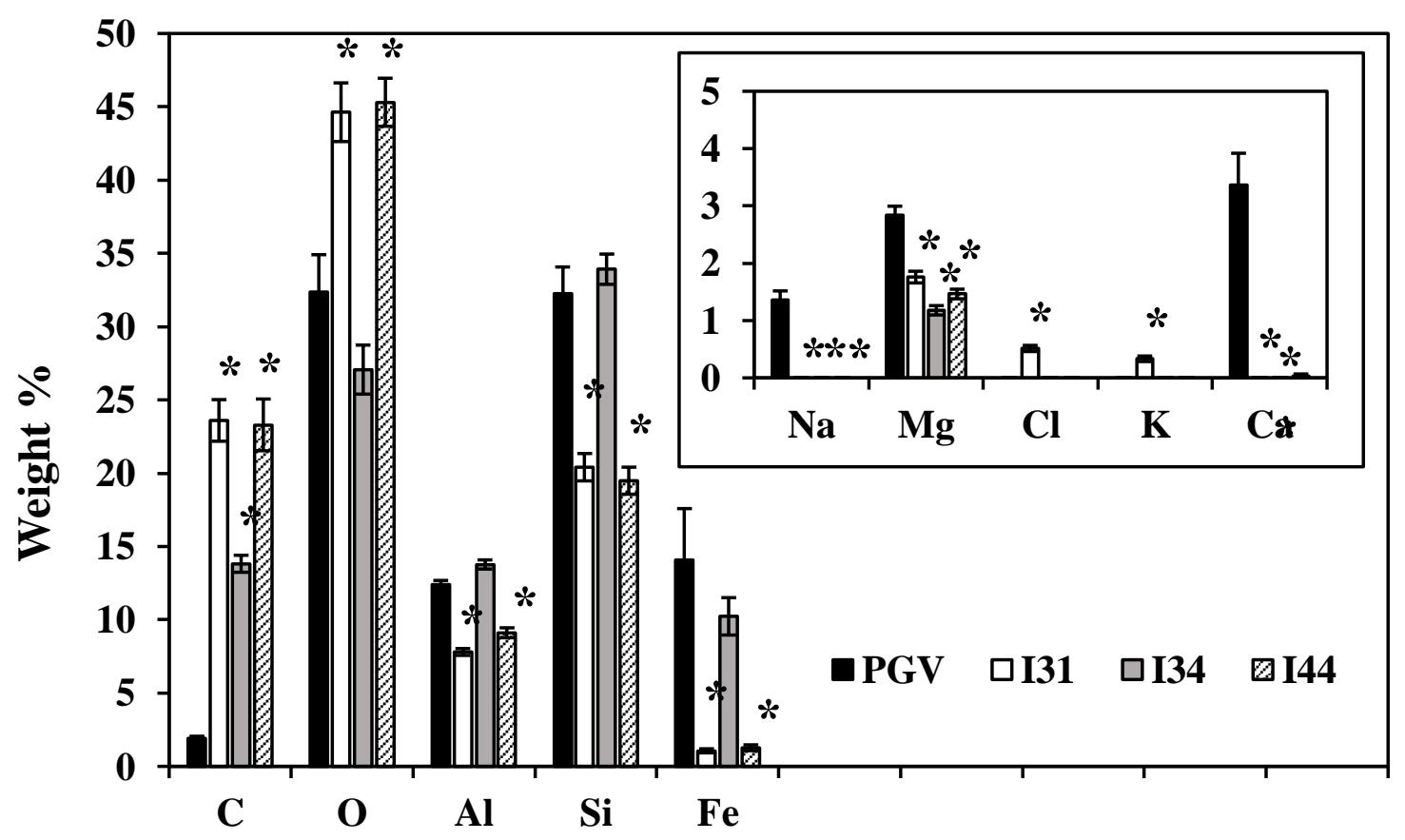

Figure 3: Elemental surface analysis of as received nanoclay as determined by energy dispersive analysis (EDX). Mean area under the curve from EDS spectra were calculated and compared. Inset depicts trace element $\%$ weight. * and $\sim$ indicate significant differences compared to PGV and as-produced counterpart, respectively $(\mathrm{p} \leq 0.05)$. 


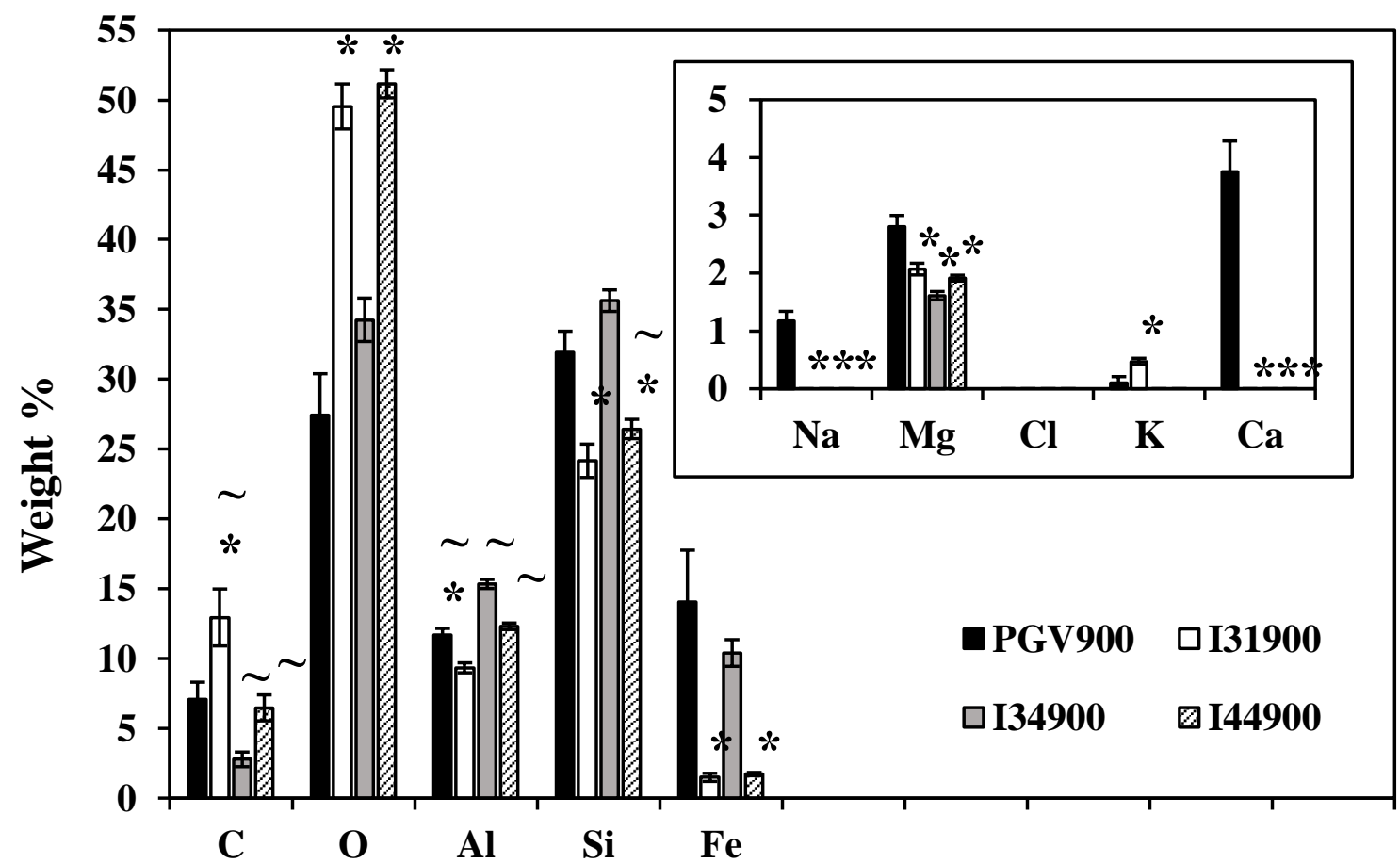

Figure 4: Elemental surface analysis of incinerated byproduct of pristine nanoclay as determined by energy dispersive analysis (EDX). Mean area under the curve from EDS spectra were calculated and compared. Inset depicts trace element $\%$ weight. $*$ and $\sim$ indicate significant differences compared to PGV and as-produced counterpart, respectively $(\mathrm{p} \leq 0.05)$.

Lastly, our analysis of the hydrodynamic particle size in different inert and cell culture media (Phosphate Buffer Saline-PBS and Dulbecco's modified Eagle medium-DMEM respectively), showed that I31 and I34 had smaller sizes (sub-micron range) in DMEM than pristine nanoclay PGV or I44 (Table 1 and Figure 5). These size differences are likely due to nanoclay- or nanoclay coating-medium interactions, leading to such events as protein corona formation ${ }^{41}$ and particle repulsion. ${ }^{42}$ 


\begin{tabular}{|c|c|c|c|c|c|c|c|c|c|}
\hline & & PGV & I31 & I34 & I44 & PGV900 & I31900 & I34900 & I44900 \\
\hline \multirow{3}{*}{ DMEM } & $<10 \%$ & $2.46+/-0.09$ & $0.21+/-0.01$ & $0.28+/-0.01$ & $2.97+/-0.00$ & $3.14+/-0.04$ & $0.05+/-0.00$ & $2.92+/-0.01$ & $3.27+/-0.00$ \\
\hline & $<50 \%$ & $3.70+/-0.15$ & $0.29+/-0.01$ & $0.38+/-0.01$ & $4.31+/-0.01$ & $4.60+/-0.07$ & $0.09+/-0.00$ & $4.31+/-0.01$ & $4.93+/-0.01$ \\
\hline & $<90 \%$ & $7.81+/-0.46$ & $0.53+/-0.02$ & $0.64+/-0.02$ & $8.50+/-0.02$ & $8.69+/-0.09$ & $0.15+/-0.00$ & $8.32+/-0.02$ & $9.32+/-0.03$ \\
\hline \multirow{3}{*}{ PBS } & $<10 \%$ & $3.80+/-0.02$ & $0.83+/-0.59$ & $0.21+/-0.01$ & $2.86+/-0.00$ & $0.90+/-0.79$ & $2.53+/-0.00$ & $3.02+/-0.00$ & $3.11+/-0.00$ \\
\hline & $<50 \%$ & $6.08+/-0.03$ & $1.27+/-0.95$ & $0.29+/-0.02$ & $4.24+/-0.01$ & $1.33+/-1.16$ & $3.66+/-0.01$ & $4.44+/-0.19$ & $4.73+/-0.00$ \\
\hline & $<90 \%$ & $12.25+/-0.20$ & $2.48+/-1.93$ & $0.5+/-0.03$ & $8.28+/-0.03$ & $2.57+/-2.23$ & $6.86+/-0.01$ & $8.97+/-0.01$ & $9.06+/-0.01$ \\
\hline
\end{tabular}

Table 1: Hydrodynamic diameter distributions of suspended as-produced and incinerated byproduct of pristine nanoclay and ONCs in BEAS-2B culture medium and PBS. Values represent mean and SE $(n=3)$. 
Namely, hydrophilic PGV and hydrophobic I44 are more likely to strongly associate with their respective hydrophilic and -phobic regions of proteins present in the DMEM medium. On the other hand, I31 and I34, which have relative intermediate hydrophobicity compared to PGV and I44, would induce less protein adsorption to thus yield better dispersion. ${ }^{43,44}$ Furthermore, their respective modifiers containing amine (I31) and hydroxyl (I34) groups may induce varied dispersity via hydrogen bonding, van der Waals forces, and electrostatic interactions and cause clay repulsion. ${ }^{42}$ Following thermal degradation, we observed no differences in size distribution for the nanoclays thus further confirming loss of the organic modifier and ability for the previously listed interactions (Figure 5).

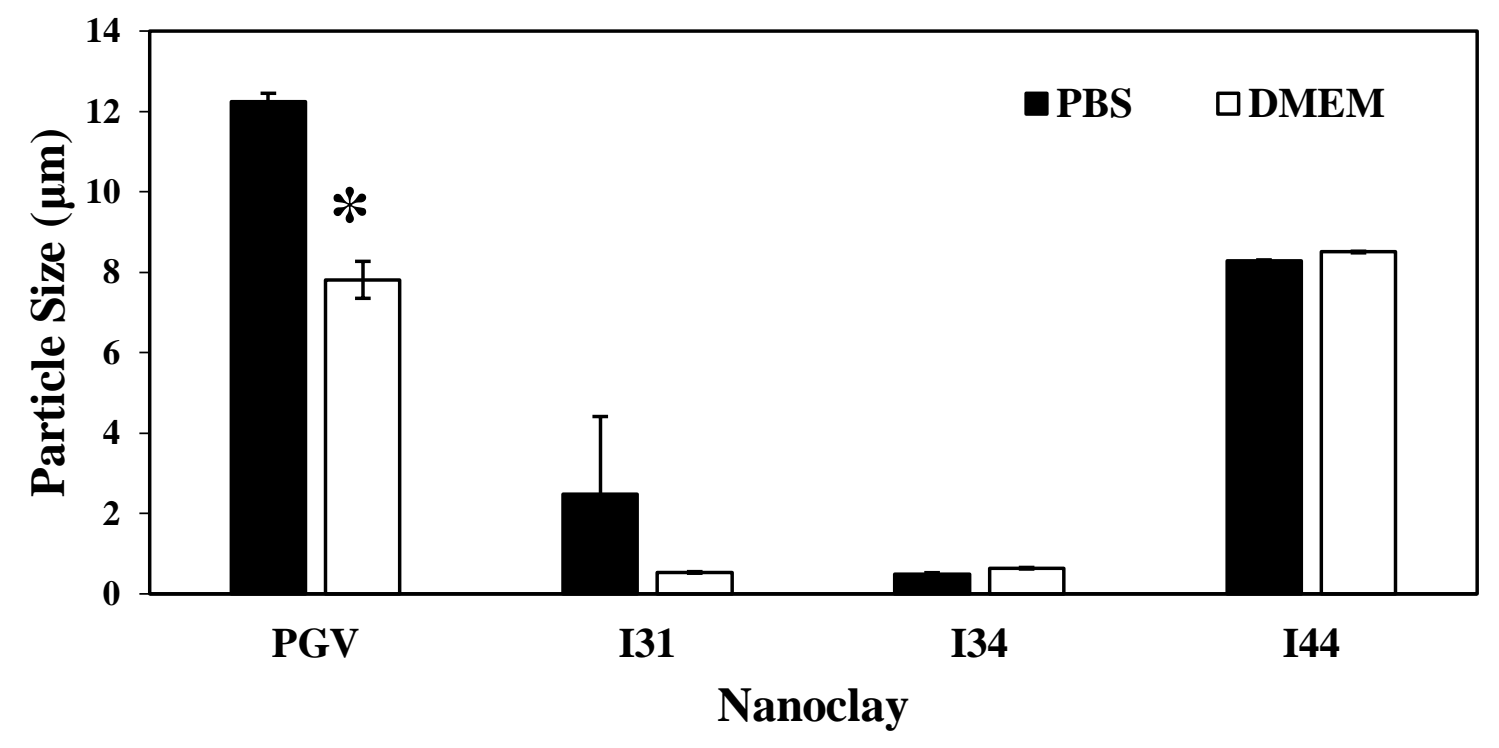

Figure 5: Hydrodynamic diameter of as-produced Nanomer nanoclays in PBS vs.

DMEM medium. * indicates a significant difference compared to PBS $\left(\mathrm{p} \leq 0.05 ; 90^{\text {th }}\right.$ percentile of particles analyzed). 


\section{High-content screening microscopy (HSC) at half maximum inhibitory concentration (IC 50)}

HCS approach was next employed to study biological indicators of cytotoxicity as resulted from exposure to pristine nanoclay and ONCs and their byproducts, namely monolayer integrity, cellular size, and nuclear distribution. For this, a confluent monolayer of BEAS-2B was used to thus mimic pulmonary function and accurately predict lung injury/response. It is known that cellcell adhesion as well as monolayer formation are integral factors in epithelial cell differentiation. ${ }^{45}$ Previous reports showed that monolayer formation regulates growth, spreading, migration, proliferation, viability, and cytoskeletal function of cells. ${ }^{46-48}$ BEAS-2B cells were considered suitable models ${ }^{49}$ since previous research showed that they could serve as an accurate in vitro system for evaluating lung-related toxicity. ${ }^{50}$ Fixed dose considered for our HCS analysis was from previously reported $\mathrm{IC}_{50}$ values for each of the nanoclays or byproducts being used in this study ${ }^{23}$ Briefly, the reported $\mathrm{IC}_{50}$ was obtained upon exposure of BEAS-2B cells to a range of different sample concentrations $\left(0-197 \mu \mathrm{m} / \mathrm{cm}^{2}\right)$; dose range was chosen to mimic exposure in manufacturing/disposal environments ${ }^{51}$ and represent a working lifetime exposure of 45 years based on $8 \mathrm{~h} /$ day and 50 weeks/year, while accounting for particle and lung characteristics. ${ }^{52}$ Analysis showed that resulting $\mathrm{IC}_{50}$ for the nanoclays and their byproducts were $325 \mu \mathrm{g} / \mathrm{mL}$ for PGV, $20 \mu \mathrm{g} / \mathrm{mL}$ for I31, $10 \mu \mathrm{g} / \mathrm{mL}$ for I34, $50 \mu \mathrm{g} / \mathrm{mL}$ for I44, $400 \mu \mathrm{g} / \mathrm{mL}$ for PGV900, $150 \mu \mathrm{g} / \mathrm{mL}$ for I31900, $200 \mu \mathrm{g} / \mathrm{mL}$ for I34900, and $175 \mu \mathrm{g} / \mathrm{mL}$ for I44900, respectively. ${ }^{23}$

High content imaging analyses showed that cells exposed to PGV (Figure 6) have a significant loss of cell monolayer coverage (up to 6.4\%) when compared to unexposed controls. This significant loss of monolayer coverage was also mirrored in cell nuclear counts. 

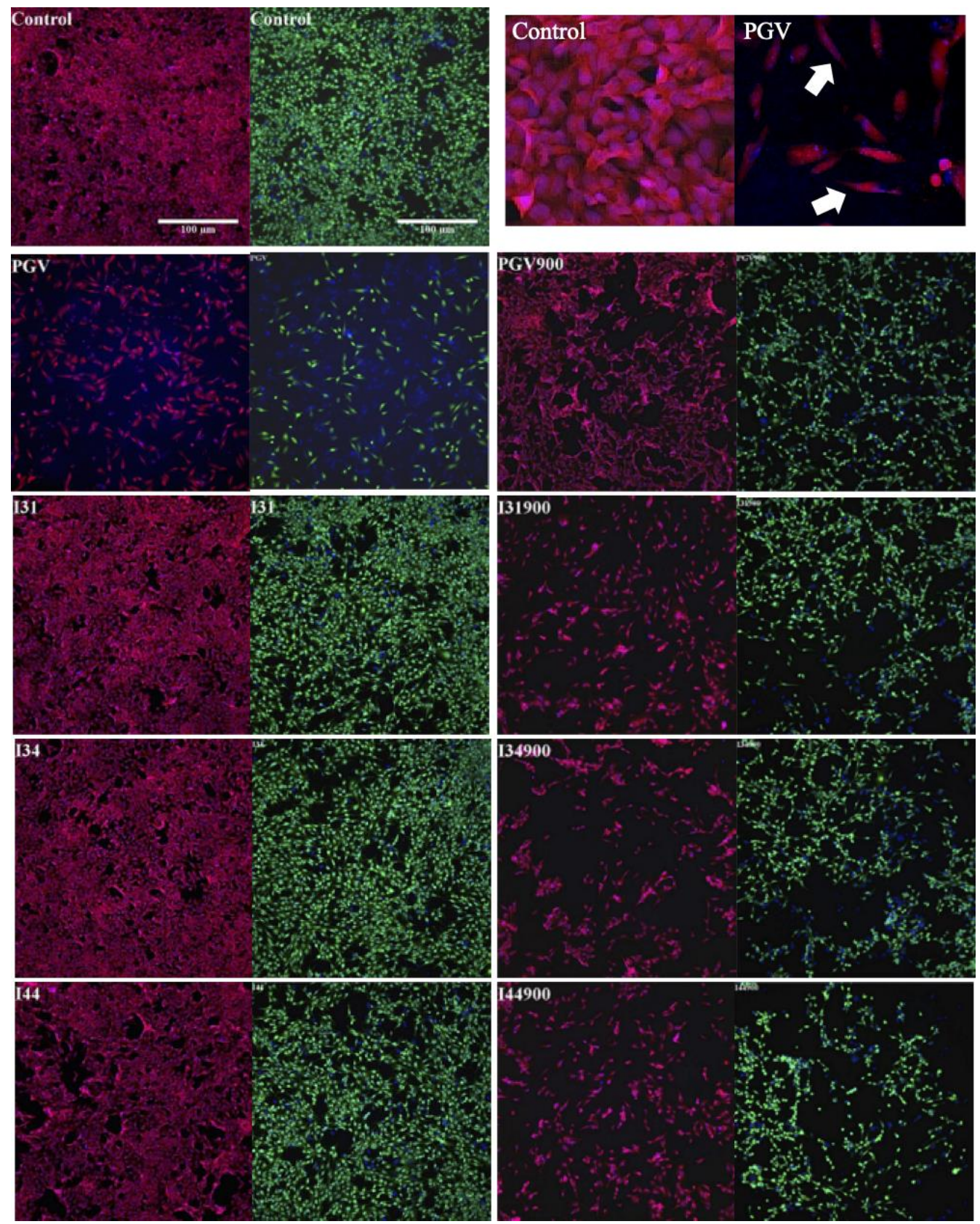

Figure 6: Representative 10x magnification images from HCS of Nanomer

organomodified nanoclay and incinerated byproduct particle exposure to human bronchial epithelial cells monolayer integrity, cell shape, and nuclear morphology. Cell membrane (red) and cytoplasm (green) fluorescent probes were imaged in separate assays with nuclear (blue) probe. White arrows indicate cell morphology change from unexposed cuboidal-shaped cells to PGV-exposed elongated cell morphology. 
Further, there were changes in the individual cell shape such as cell elongation as well as observed loss of membrane integrity (Figure 6- white arrows).

Changes in PGV-exposed cellular morphology from their typical oval nature (shown for controls) to a more stretched, spindle-shaped profile indicate a cell-survival and potential initiation of wound healing response, such as EMT. ${ }^{53}$ Relative to controls, cells exposed to I31, I34, and I44 (Figure 6) exhibited no significant changes in monolayer coverage (87\%, 91\%, and $77.2 \%$, respectively; Figure 7). Contrary, cells exposed to PGV900, I31900, I34900, and I44900 (Figure 1) showed a significant loss of cell monolayer coverage (about 55\%, 40\%, 55\%, and 32\%, respectively- Figure 7).

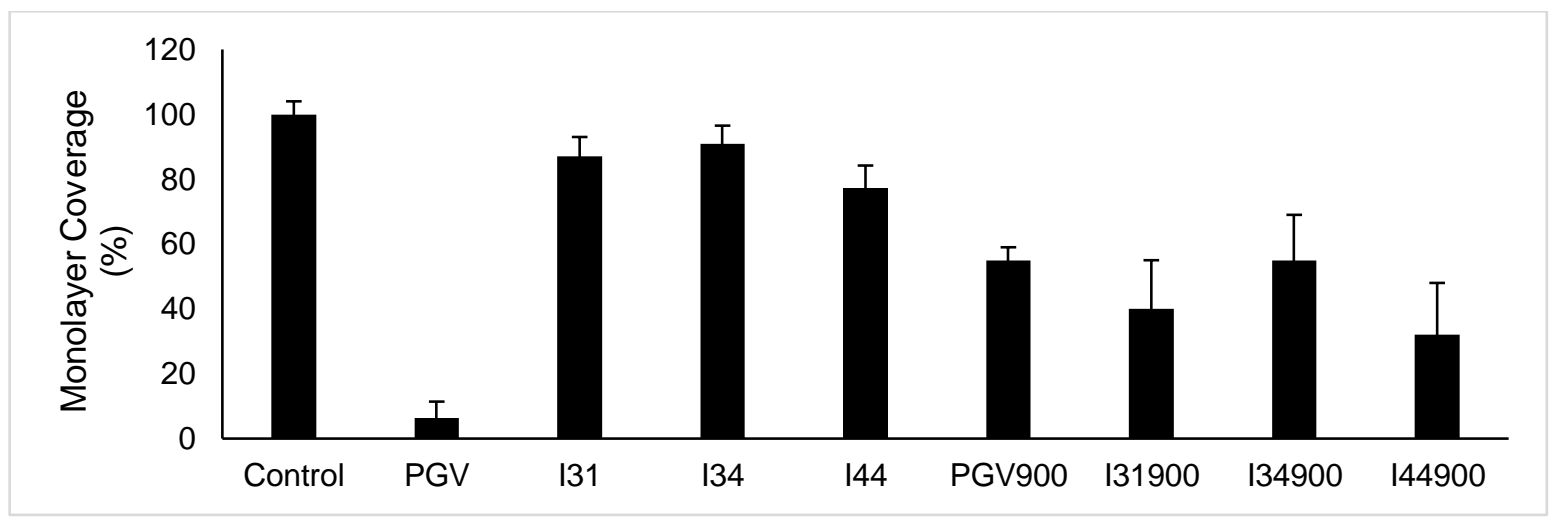

Figure 7. Quantification of HCS analysis of bronchial epithelial monolayer coverage to Nanomer organomodified nanoclay and incinerated byproduct exposure.

Moreover, cells exposed to PGV900 showed a significantly higher monolayer coverage relative to cells exposed to PGV, while cells exposed to I31900, I34900, and I44900 exhibited significantly lower monolayer coverage than their respective, as-received ONC counterparts (Figure 8). 


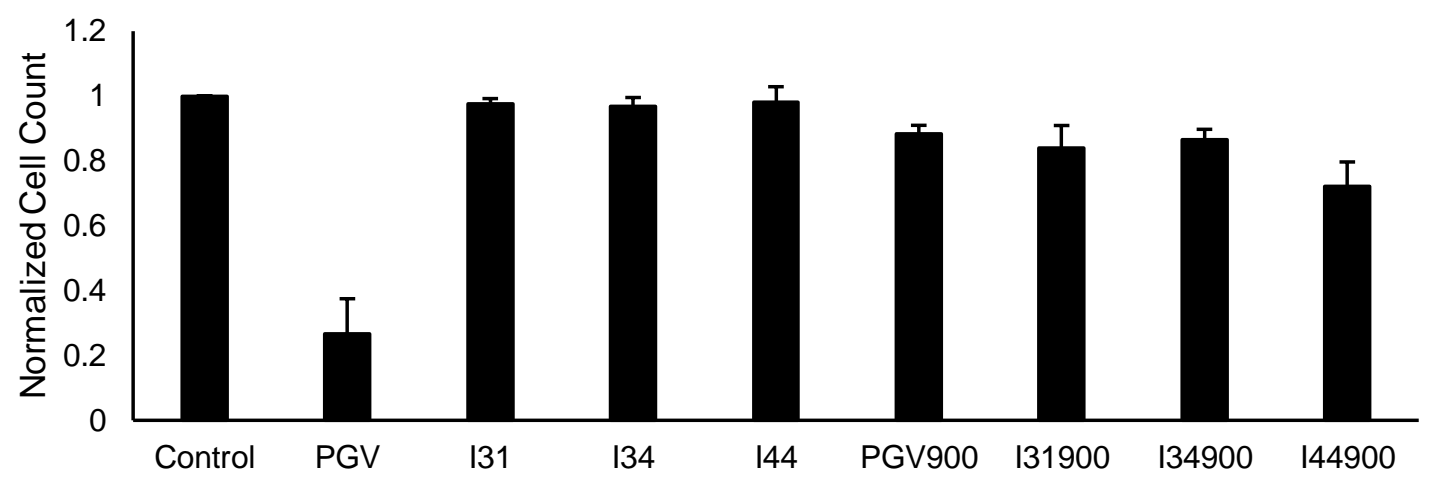

Figure 8. Quantification of HCS analysis of bronchial epithelial monolayer cell count to Nanomer organomodified nanoclay and incinerated byproduct exposure.

No significant changes to single cell area were detected upon treatment with nanoclays and byproducts with respect to the controls (Figure 9).

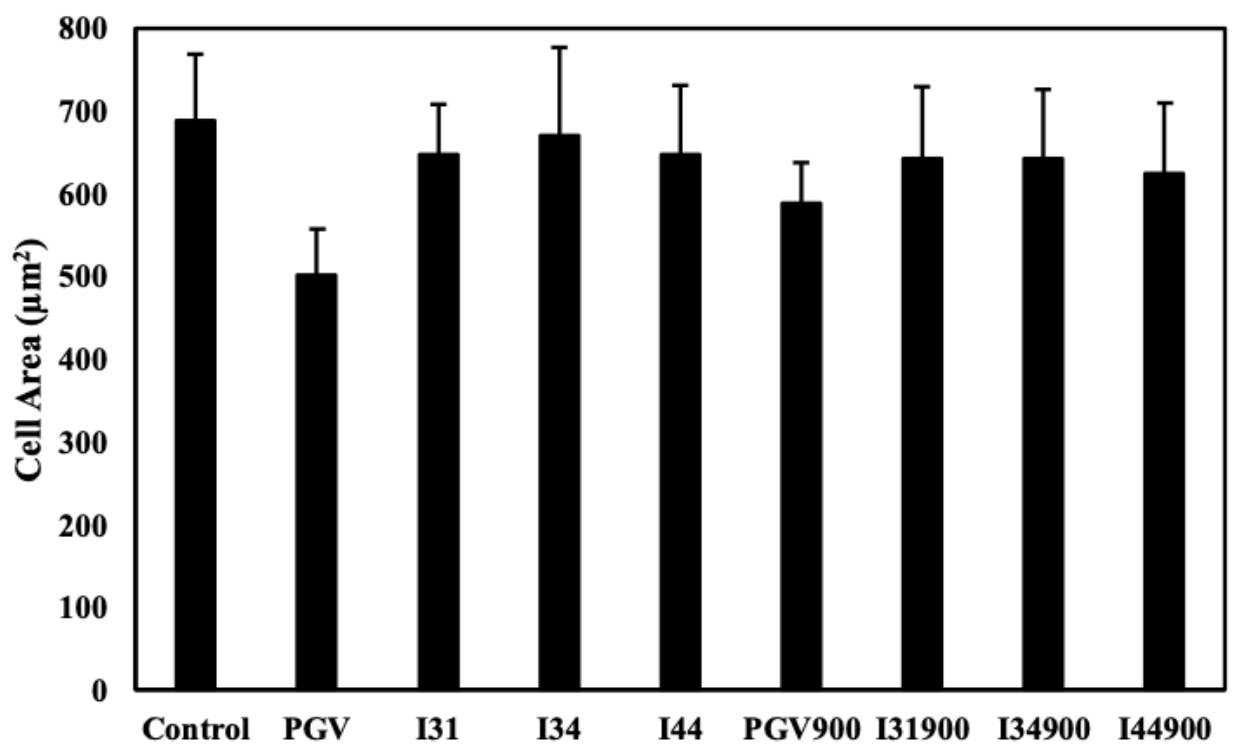

Figure 9. Single cell area of bronchial epithelial cells exposed to pre- and post-incinerated nanoclays. No significant difference was observed. 
Analysis of nuclear area of cells exposed to ONCs and byproducts relative to controls (Figure 10) showed that there was a significant loss for cells treated with PGV (average of 38.1 $\mu \mathrm{m}^{2}$ ) relative to control cells (average of $219.5 \mu \mathrm{m}^{2}$ ). Moreover, cells exposed to I44900 showed a significant $9 \%$ loss in nuclear area (from $219.5 \mu \mathrm{m}^{2}$ to $198.8 \mu \mathrm{m}^{2}$ respectively). However, cells treated with I31, I34, and I44 and their byproduct counterparts did not exhibit significant changes in nuclear area when compared to the controls.

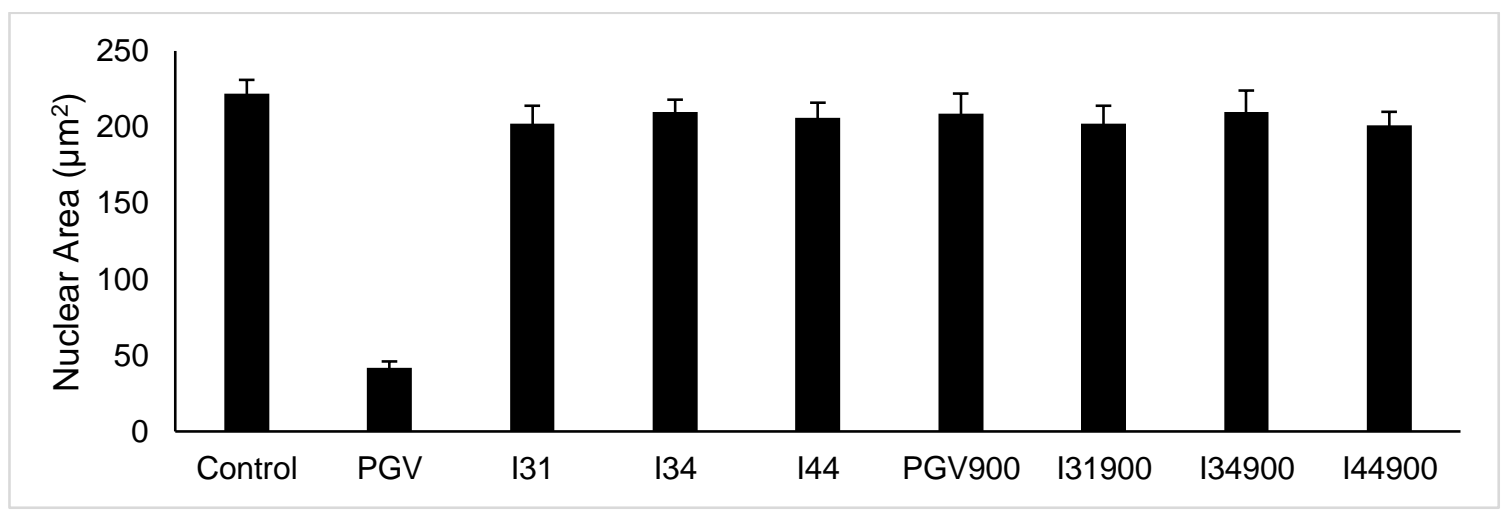

Figure 10. Quantification of HCS analysis of bronchial epithelial monolayer nuclear area to Nanomer organomodified nanoclay and incinerated byproduct exposure.

Lastly, analysis of nuclear intensity (Figure 11) revealed a significant loss for cells exposed to PGV (59\%), relative to control cells. Yet, cells treated with I31, I34, and I44 exhibited no significant changes when compared to controls (i.e., 13\%, 7\%, and 7\%, respectively). Cells exposed to PGV900 also did not exhibit significant change in nuclear intensity (14\%) relative to controls, while exposure to I31900, I34900, and I44900 caused significantly higher nuclear intensities (i.e., 32\%, 24\%, and 29\%, respectively) than control values. Furthermore, it was noted 
that cells exposed to PGV900, I31900, and I44900 exhibited significantly higher nuclear intensities than their respective, as-received counterparts.

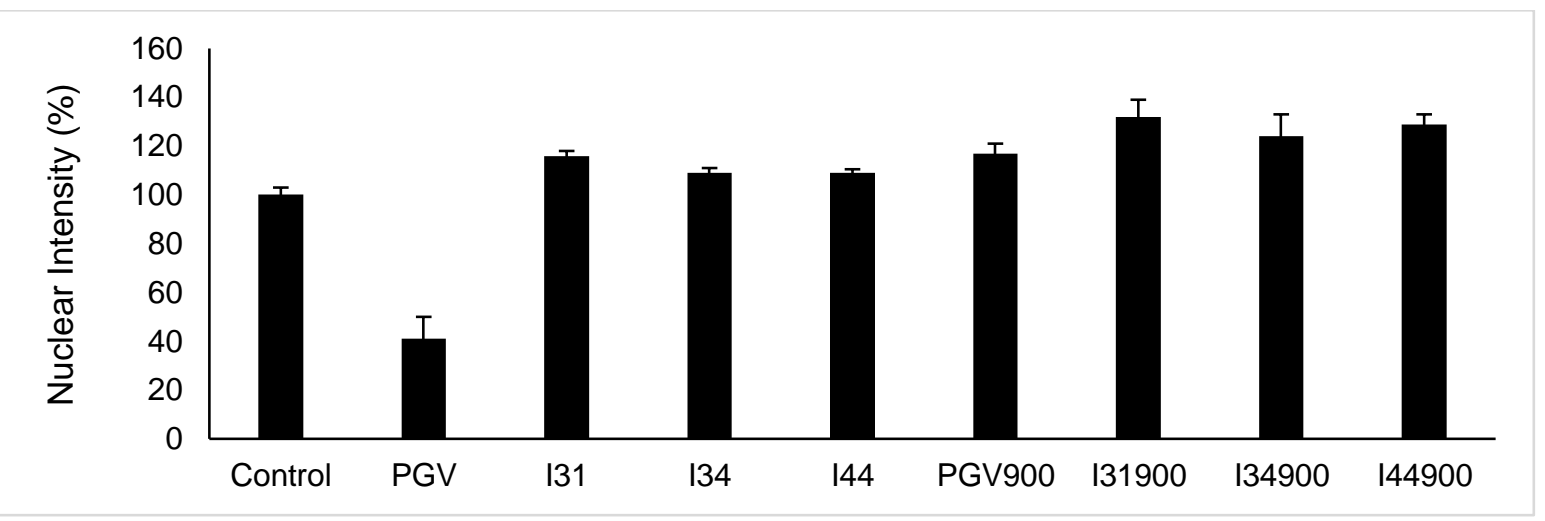

Figure 11. Quantification of HCS analysis of bronchial epithelial monolayer nuclear intensity to Nanomer organomodified nanoclay and incinerated byproduct exposure.

The above analysis show that use of HCS provides a rapid, automated, and unbiased assessment of cell changes as well as a quantitative information on cell counts, cell area, monolayer coverage, and nuclear integrity. The analysis complements previously reports on montmorillonite and fine-sized silica particulate (such as incinerated nanoclay byproduct) which showed both cell damage and cytotoxicity. ${ }^{54}$ Mechanisms of silica lung toxicity was shown to include cell membrane penetration, cell lysis, oxygen radical generation, vascular permeability, edema, mitochondrial depolarization, acute and chronic inflammation, apoptosis, pyroptosis, and altered epithelial signaling responses. ${ }^{54-58}$ Except for PGV-exposed cells, loss of monolayer coverage did not align with cell counts indicating that another mechanism besides cytotoxicity might be driving a decrease in monolayer integrity for the byproducts being tested. An increase in nuclear intensity 
(i.e., greater DNA material) with no change in nuclear area associated with monolayer integrity loss suggests that surviving bronchial epithelial cells exposed to byproducts had entered a different cell cycle phase compared to unexposed and ONC-exposed cells. Bronchial epithelial cells, upon exposure to PM2.5 and other fine particulate, usually display transient G2 arrest, Reactive Oxygen Species (ROS), and inflammation prior to undergoing either apoptosis or wound healing repair acitivity. ${ }^{59-61}$ Such HSC results complement previous studies by Stueckle et al., showing that in vivo Day 1 post-exposure to mouse lung that both Cloisite $\mathrm{Na}$ and incinerated Cloisite $\mathrm{Na}$ (similar to PGV and PGV900) exhibited acute lung damage and inflammation in collected bronchoalveolar lavage fluid and histopathological analysis.. ${ }^{20}$ Conversely, Cloisite 30B (with a similar I34 coating) displayed a delayed, moderate increase in lung damage at Day 7 with minimal damage at Day 1 post-exposure.

\section{Real-time assessment of cellular behavior}

BEAS-2B cellular behavior before and after exposure to nanoclays and byproducts was also analyzed as a function of changes in cell-induced impedance signals. ECIS analysis were considered to supplement HSC results since previous reports showed that such screening strategy provides a real-time, high-throughput, non-invasive analysis of quantitative changes in cell morphology and cell-substrate interactions that could be used to monitor behavior, morphology, attachment, ${ }^{26}$ and movement of cells. ${ }^{37,62}$ We and others have previously shown the ability of ECIS to monitor cells exposed to a variety of nanomaterials through such real-time, highthroughput, label-free approach. ${ }^{24,} 28,63$ Representative ECIS measurements of normalized resistance values of cells exposed to $\mathrm{IC}_{50}$ of nanoclays and byproducts were performed for $48 \mathrm{~h}$ at $4 \mathrm{kHz}$ frequency and are shown in Figure 12a (nanoclays) and b (byproducts) respectively. 

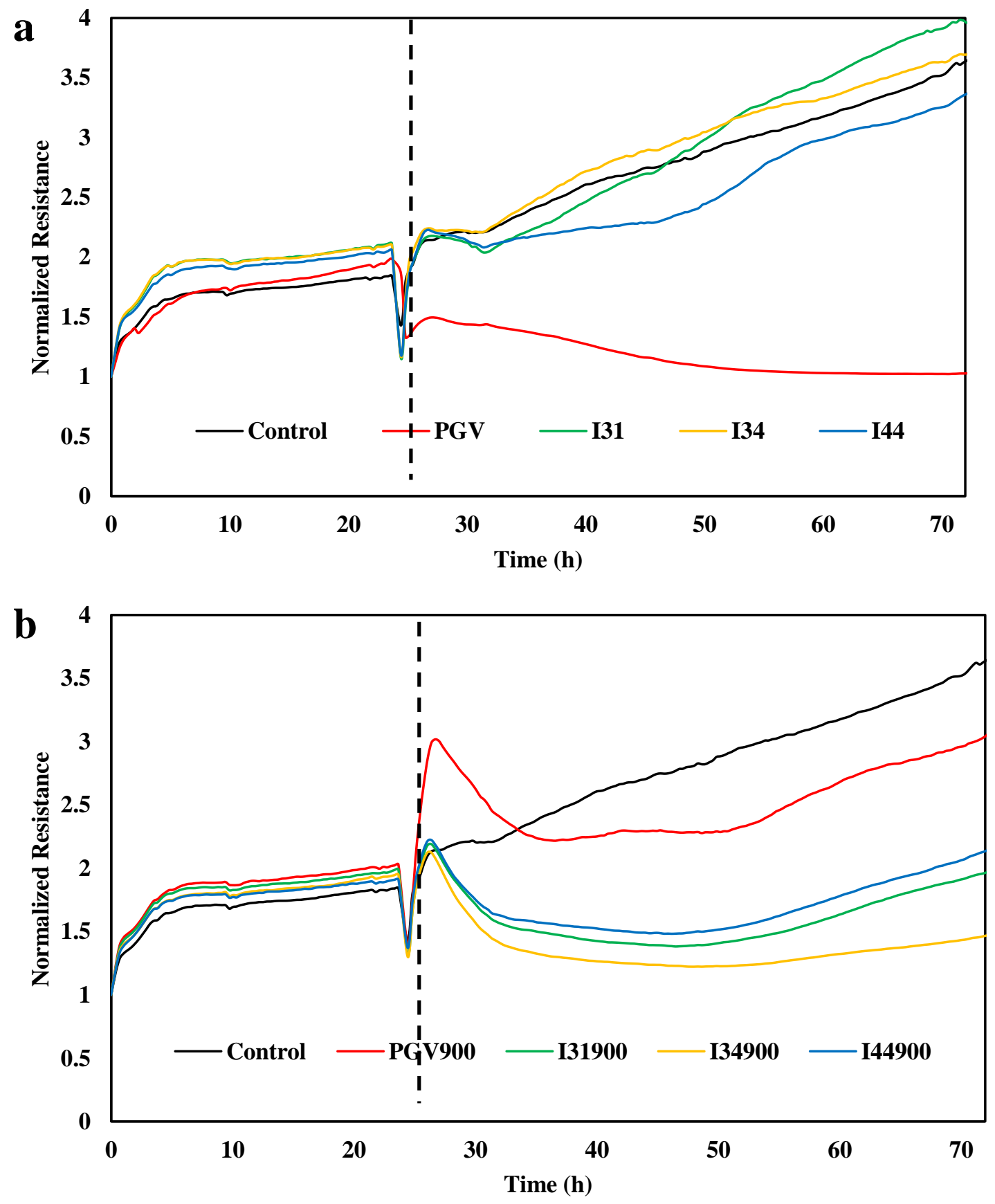

Figure 12. Representative measurements of normalized resistance upon exposure for $48 \mathrm{~h}$ to (a) nanoclays and (b) byproducts. 
Chosen operational frequency was previously shown to be optimal for measurements of cellular behavior such as cellular membrane integrity, attachment, and cell-cell interactions. ${ }^{64,65}$ Our results showed that upon cell seeding, the normalized resistance values increased with time, due to an increase in sensing area known to be a result of cells settling and interfacing with the electrodes during the $24 \mathrm{~h}$ of monolayer formation. ${ }^{28,62}$ As the seeded cells developed a confluent monolayer, resistance values tapered off to constant values. ${ }^{26}$ After monolayer coverage was recorded, cells were exposed to $\mathrm{IC}_{50}$ concentrations of each nanoclay or byproduct in real-time, as described above.

Figure 12a indicates that exposure to nanoclays induced time- and treatment-dependent cellular behavior. Specifically, there was an initial loss of resistance for all exposed cells which was attributed to the electrode disconnection to ensure cell exposure, followed by an increase in resistance for all cells except those exposed to PGV. Cells exposed to PGV lost all resistance within $24 \mathrm{~h}$ of treatment and exhibited no recovery during the $48 \mathrm{~h}$ of observation. Within the period of 2-7 h of exposure, the cells exposed to I31 and I44 showed a slight loss in resistance with respect to controls. From 7-24 h, cells exposed to I34 exhibited similar behavior to control cells and a slightly higher resistance, while those exposed to I31 recovered to a resistance value similar to that of the controls. Exposure to I44 induced a loss in resistance also relative to control cells. Furthermore, within the 24-36 h of observation, it was noted that cells exposed to I34 showed no changes in resistance behavior overall however held a slightly higher resistance than controls. Complementary, cells treated with I31 and I44 also exhibited a slight rise in resistance relative to controls. From 36-48 h of observation, no changes in resistance were observed for any of these exposed cells, all relative to controls. Final resistance values for cells treated with I31, I34, and 
I44 were of similar trends to controls, with slightly higher and lower values for I31 and I44, respectively.

Analysis of cellular monolayers exposed to byproducts are shown in Figure $12 \mathrm{~b}$ and also reveal both time- and treatment-dependent response, however with major overall differences relative to nanoclays. Specifically, after an observed initial loss of resistance for all cells (again attributed to the disconnection from the electrode), within the first $2 \mathrm{~h}$ of exposure there was an increase in resistance more so for cells treated with PGV900. From 2-10 h, cells exposed to all 4 byproducts showed a loss in resistance relative to controls. While resistances of cells exposed to I31900, I34900, and I44900 were far less than controls, those exhibited by cells exposed to PGV900 were only slightly less than those of the control. During the period of 10-28 h of exposure, no additional changes in resistance were observed. Finally, from $28-48 \mathrm{~h}$ of observation, cells exposed to all byproducts exhibited steady recovery of resistance however to values far less than those observed for the controls. Relative to one another, I34900 induced the greatest loss in resistance, while I44900 caused the lowest.

Given that one of the cytoskeleton's functions is to regulate cell-substrate interactions ${ }^{66}$ and that changes in cellular adhesion may be associated with changes in both cellular morphology ${ }^{67}$ and elasticity, ${ }^{68,69}$ we also evaluated changes in cell adhesion (i.e., $\alpha$ value) properties upon exposure to nanoclays or byproducts. Figures $13 \mathrm{a}$ and $\mathrm{b}$ assess whether there were any restrictions of current pathways beneath the cell monolayers as imposed by such exposures. ${ }^{26,}$ 27 

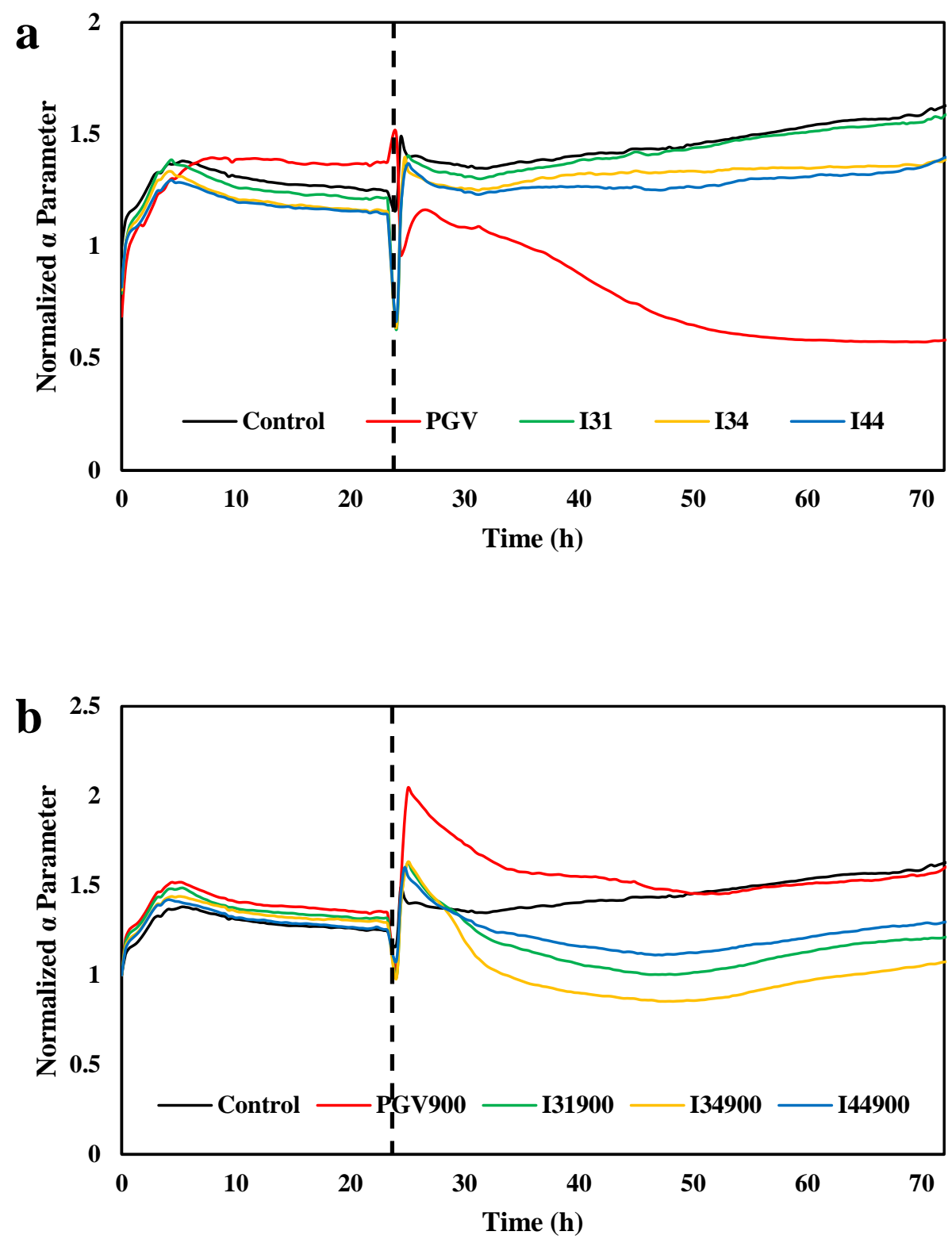

Figure 13. Representative measurements of normalized $\alpha$ parameter after $48 \mathrm{~h}$ of exposure is shown for (a) nanoclays and (b) byproducts $(n=4)$. Horizontal dashed lines indicate start of particle exposure. 
As with the overall resistance measurements, an initial loss of $\alpha$ value was noted for all cells (Figure 13a). Within the first hour of exposure however, there was an increase in $\alpha$. Also, similar to the resistance measurements, PGV induced an immediate and steady reduction in adhesion with no observed recovery of the cells over the $48 \mathrm{~h}$ of observation, all relative to control. While cells exposed to I31 exhibited no significant change in cell attachment with respect to the controls, exposure to I34 and I44 caused slight, gradual reduction in adhesion during the last $36 \mathrm{~h}$ of evaluation. Correspondingly, during the first hour of exposure, an increase in adhesion was observed for all cells exposed to byproducts (Figure 13b). Also, similar to the overall resistance, exposure to PGV900 induced a more dramatic increase in $\alpha$ when compared to the other byproducts or controls.

Overall treatment with all 4 byproducts induced a similar trend of changes in $\alpha$ as it did for changes in overall resistance. Namely, it was noted that values for attachment fell with respect to controls for $2-10 \mathrm{~h}$, began to stabilize from $10-26 \mathrm{~h}$, and recovered slightly during the remaining time of observation (up to $48 \mathrm{~h}$ ). It should also be noted that cells exposed to PGV900 exhibited higher $\alpha$ during the initial 2-26 h however fell back to levels similar to controls for the rest of the observation time. Exposure to the other byproducts induced loss of $\alpha$ with respect to controls; full recovery of $\alpha$ was not observed for any of the samples. Relative to one another, I34900 induced the greatest loss of $\alpha$, while I44900 caused the lowest. Our results complement previous studies that showed silica exposure changes bronchial epithelial cell adhesion, attachment, and cell-to-cell signaling (Kasper et al. 2011, Perkins et al. 2015). Epithelial cells under enhanced inflammatory signaling were also shown to exhibit increased adhesion abilities, which were partially mediated via inflammatory cytokines and NFאB signaling (Leir et al. 2003, Ward et al. 2015). 
These observed changes in both resistance and $\alpha$ show that organically modified nanoclays or byproducts induce a time- and dose-dependent cellular behavior thus confirming the above HSC studies and possibly hinting as changes in cell cycle,${ }^{70}$ attachment,${ }^{71}$ viability, ${ }^{72}$ and morphologyduring cell death. ${ }^{37,62}$ For instance, cells exposed to PGV lost all resistance during exposure, further confirming cell death and loss of monolayer coverage while exposure to ONCs however induced varying degrees of changes in monolayer resistance and recovery, dependent on the type of organic modifier, as shown in HSC screening. Our observations also show that the first $10 \mathrm{~h}$ of exposure are the most critical and need to be monitored since they yielded significant changes for cells exposed to almost all nanoclays and byproducts (with the exception of I34 for the resistance measurements). These changes are presumably due to differentiation of cellular internalization. ${ }^{73}$ Indeed, our physicochemical analyses have shown that organo-modification and thermal degradation significantly changed the degree of hydrophobicity and particle-medium interactions. Such parameters were previously shown to influence internalization (e.g., for a variety of materials from titanium dioxide, to organically modified silica, and carbon nanotubes) with such process to occur in the first few hours of exposure ${ }^{74-77}$ and be influenced by material's geometry and size, ${ }^{75}$, ${ }^{78}$ surface functionalization, ${ }^{79}$ and degree of hydrophobicity. ${ }^{23}$ The influence on cell behavior was shown to persist with changes in elastic properties or cycle all the way to $12 \mathrm{~h}$ of observation. ${ }^{80}$ Although cells exposed to I31 and I44 exhibited reduction of resistance initially, we observed their recovery to values similar to those of the controls. This suggests either overall cellular recovery or adaptation to the environment. Indeed, Kim et al., previously found that cells can adapt to nanoparticle uptake and still continue their cell cycle. ${ }^{81}$ It should be noted, however, that this recovery of resistance was not observed for cells exposed to the byproducts, further indicating different possible mechanism of toxicity. 


\section{Evaluation of early/late apoptosis, necrosis and cell metabolism}

With the above results and complementing studies by Yoshida et al., showing that organically modifying particles with amine or carboxyl groups reduces the amount of generated reactive oxygen species and DNA damage in HaCaT and TLR-1 cells ${ }^{82}$ and Sharma et al., showing that genotoxic effects of nanoclays, such as DNA strand-breaks, in Caco-2 cells were induced by the presence of quaternary ammonium compounds $(\mathrm{QAC}) \mathrm{s},{ }^{83}$ we were also motivated to identify any programmed cell death.
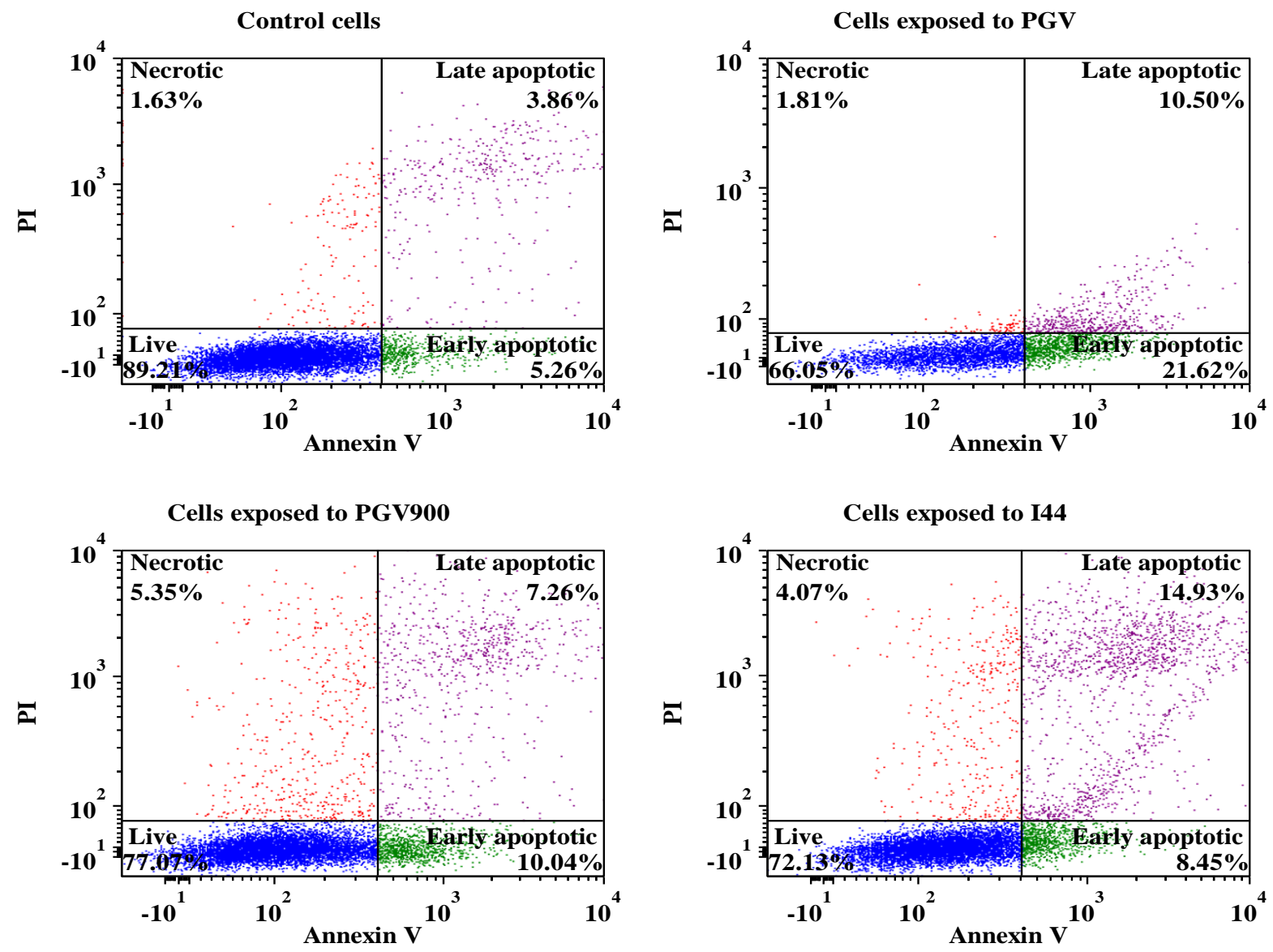

Figure 14. Flow cytometric analysis of the effect of treatment on cell apoptosis and necrosis. Representative flow cytometry scatter plots. 
To ensure high-throughput screening and thus complement both HSC and ECIS, we employed flow cytometry of cells stained with Annexin V-FITC, and PI. Representative flow cytometry scatter plots of control (unexposed) cells and cells treated with nanoclays or byproducts are shown in Figure 14. Representative flow cytometry scatter plots of particle-only controls illustrating the effects of particle-dye interactions are shown in Figure 15-18.
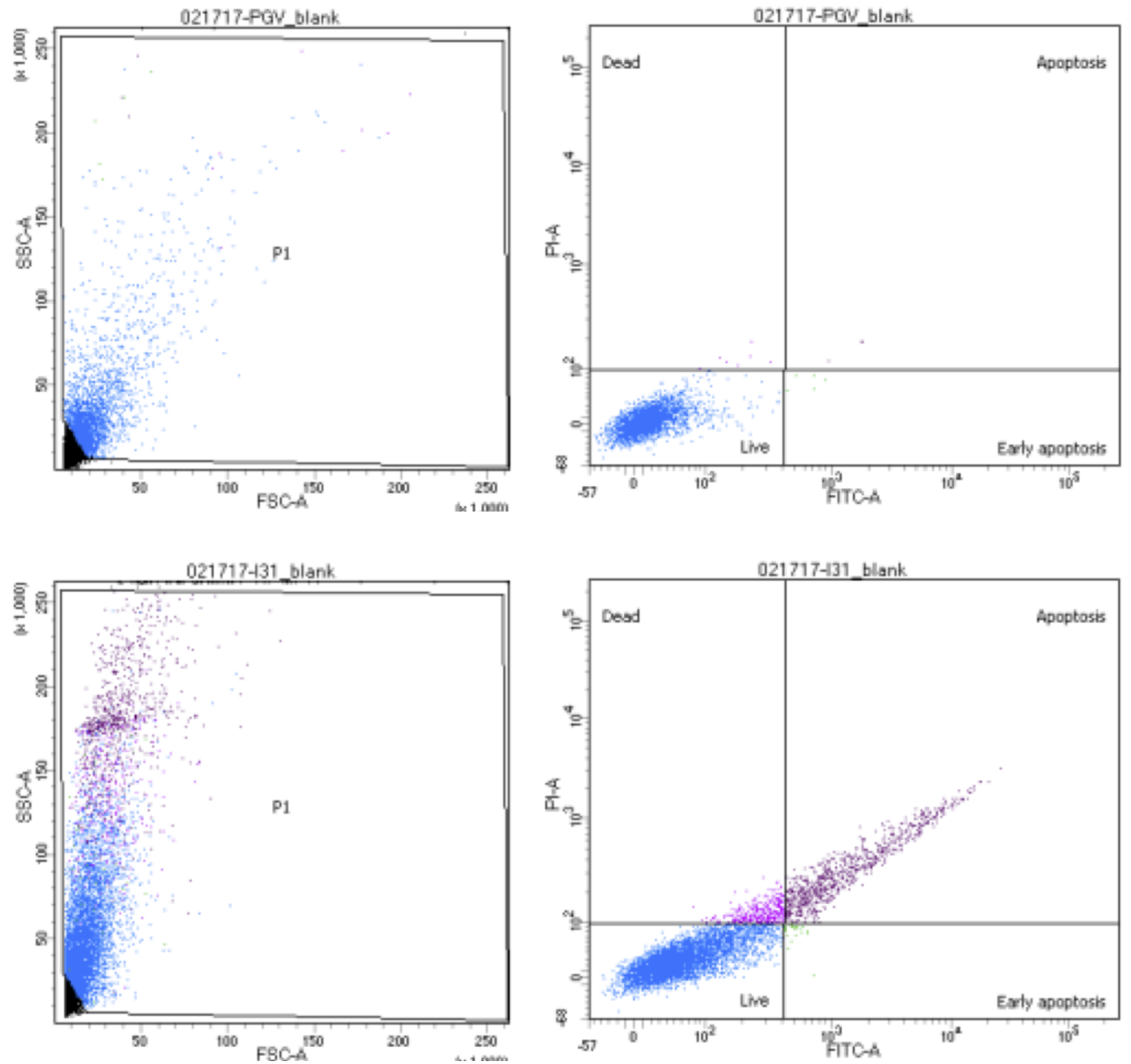

Figure 15. PGV/I31 particle-only control samples for apoptosis flow cytometry analysis. 

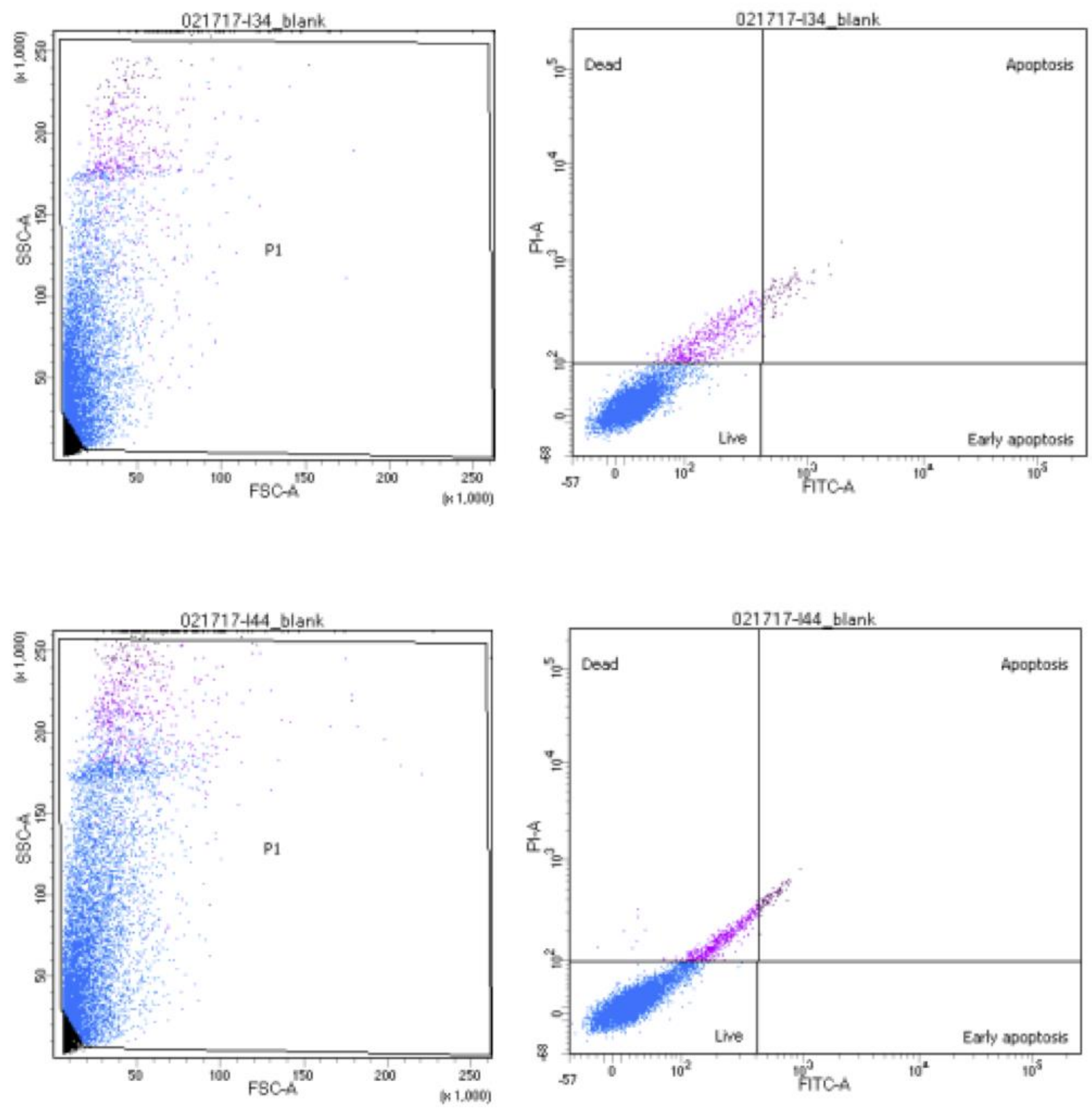

Figure 16. I34/I44 particle-only control samples for apoptosis flow cytometry analysis. 

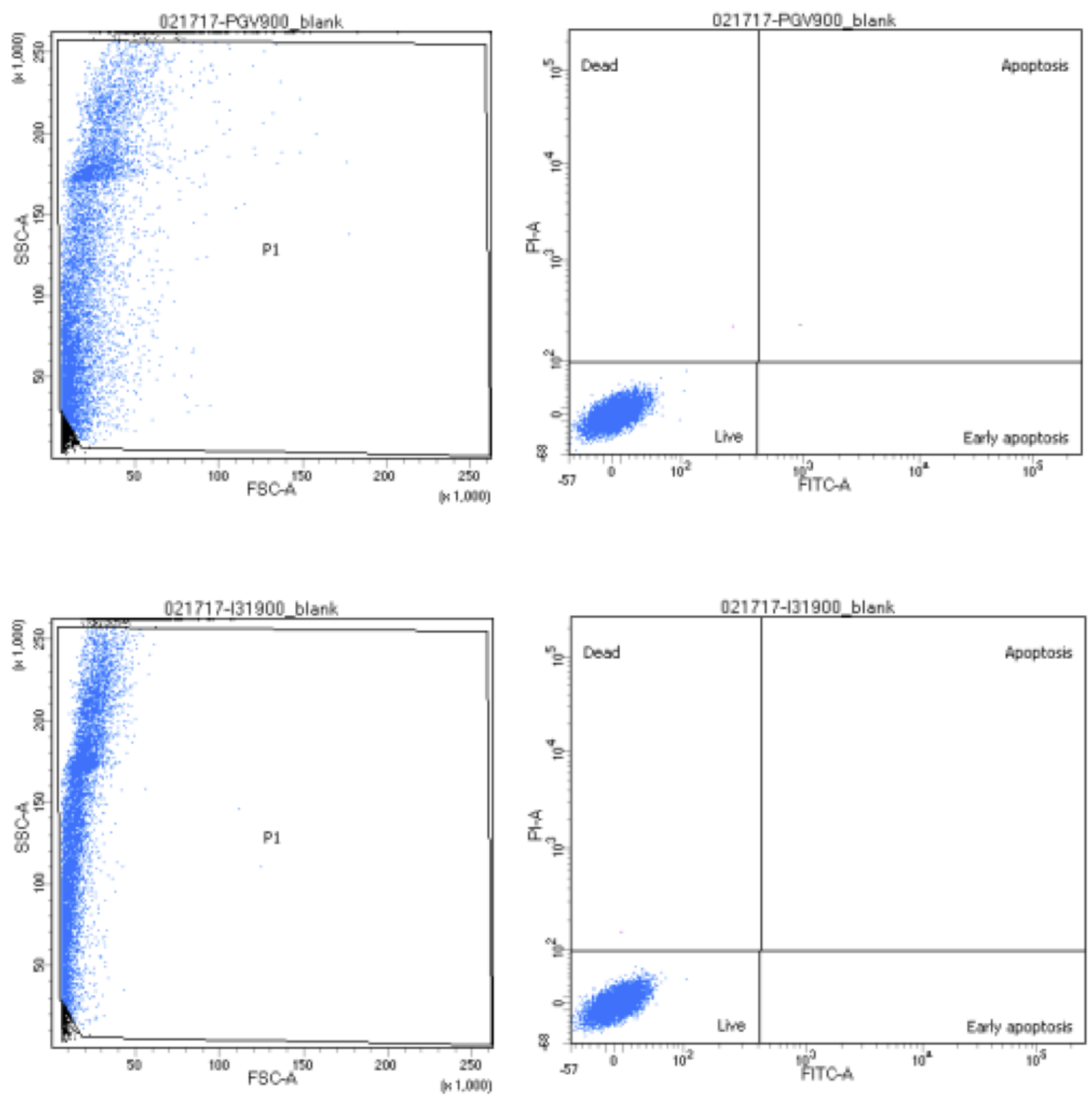

Figure 17. PGV/I31900 particle-only control samples for apoptosis flow cytometry analysis. 

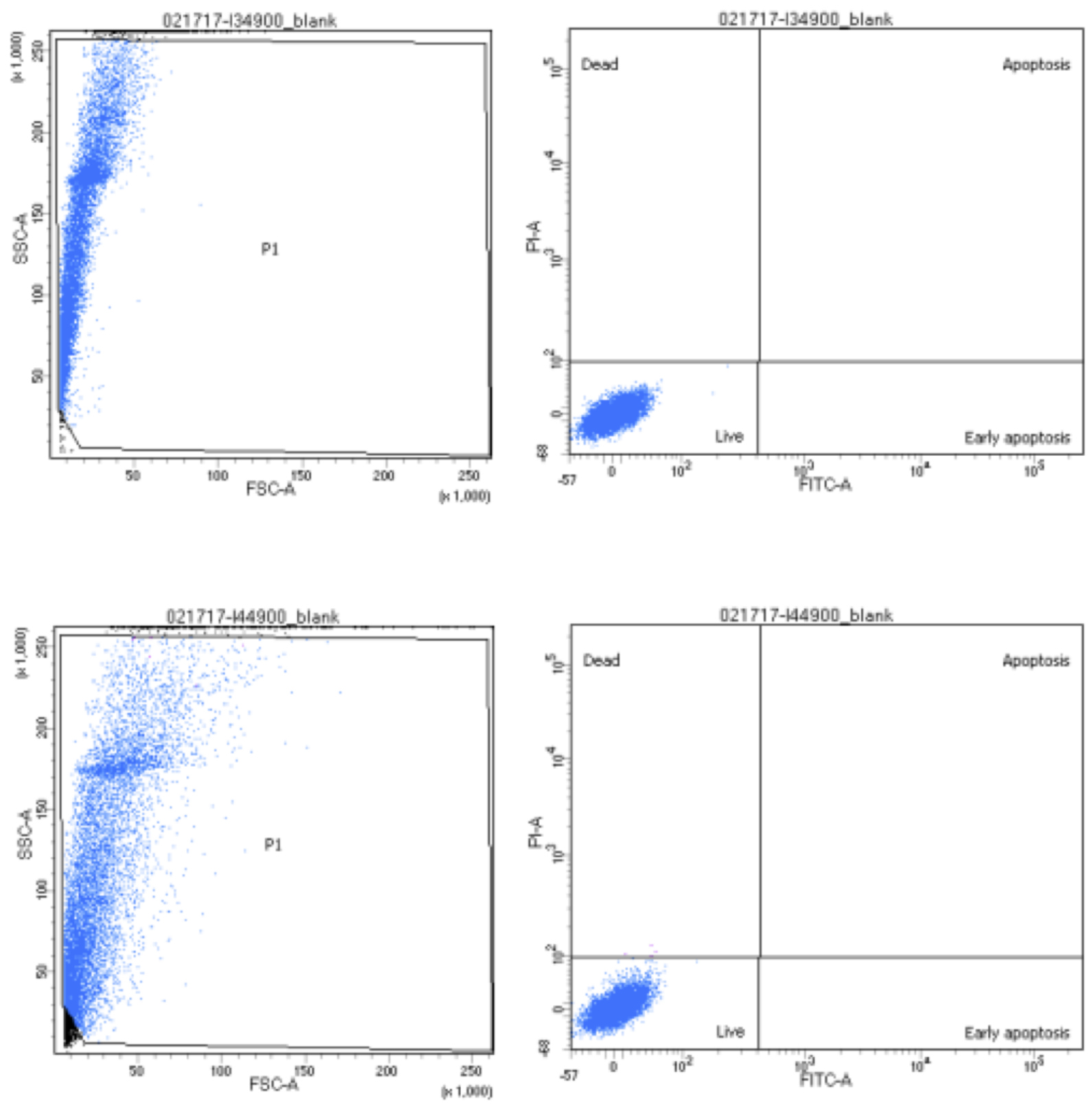

Figure 18. I34900/I44900 particle-only control samples for apoptosis flow cytometry analysis.

Our analysis (Figure 19) showed that significantly higher levels of apoptosis and necrosis were induced, relative to control cells, following short-term exposure (for $24 \mathrm{~h}$ ) to $\mathrm{IC}_{50}$ 
concentrations of both nanoclays and byproducts. Specifically, exposure to both PGV and I31 induced significantly higher percentages of cells in early apoptosis (23\% and $13 \%$, respectively) relative to control cells (3\%). However, exposure to I34 and I44 did not induce significantly higher percentages of cells in early apoptosis (6.56\% and $6.08 \%$, respectively).

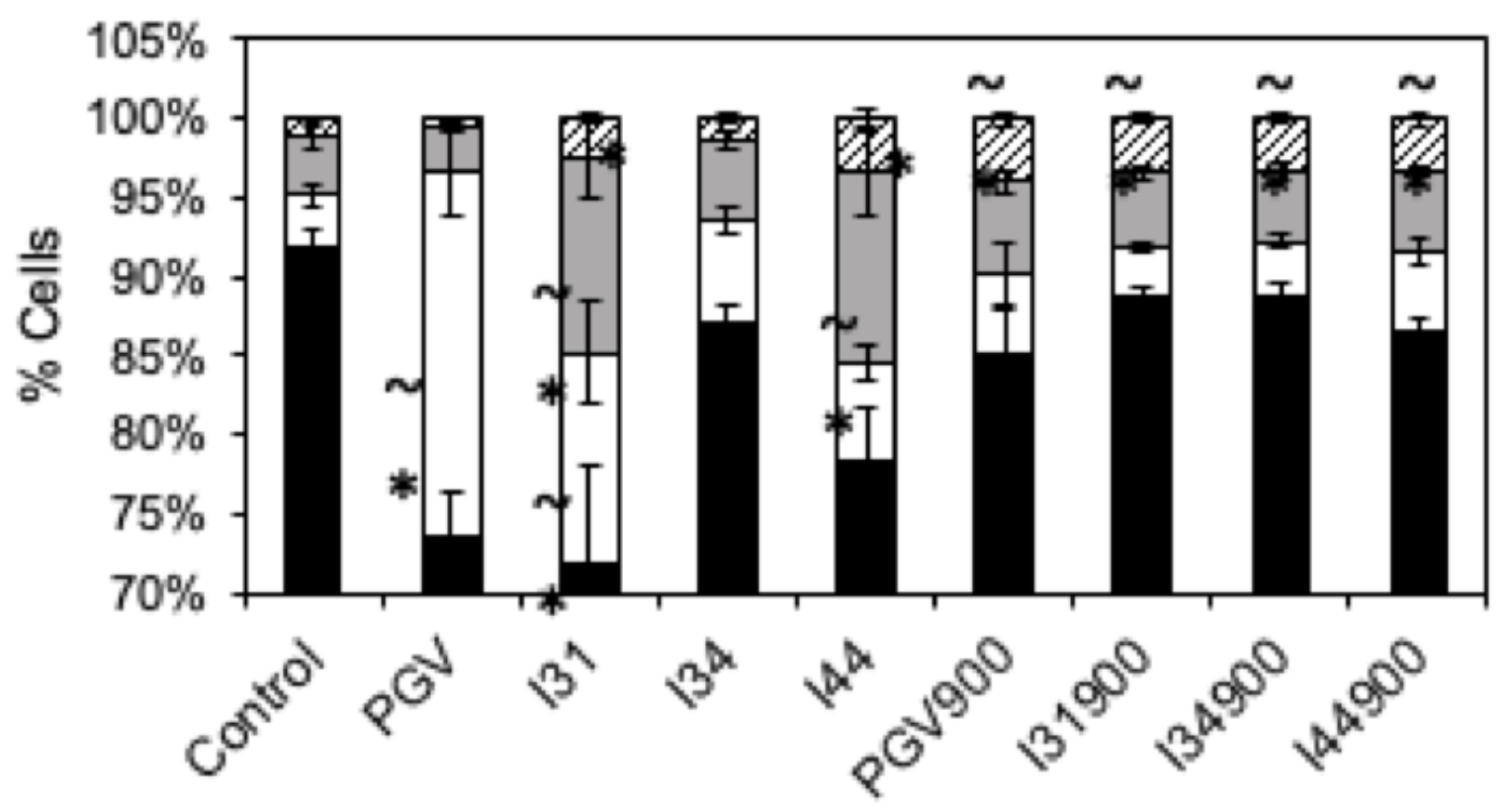

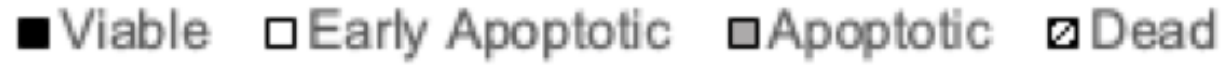

Figure 19: Flow cytometric analysis of the effect of treatment on cell apoptosis and necrosis. Quantitative comparison of live, apoptotic, and necrotic cells. * indicates significant difference between exposed samples and controls; indicates significant difference between nanoclays and the corresponding thermally degraded byproduct $(\mathrm{p}<0.05)$. 
Additionally, we observed significantly higher percentages of cells in late apoptosis upon exposure to I31 and I44 (12\% each) relative to control cells (3.6\%). Neither PGV nor I34 induced significantly higher percentages of late apoptotic cells (2.98\% and $4.93 \%$, respectively). Levels of necrotic cells were significantly higher than controls (1.2\%) following exposure to I31 and I44 (2.4\% and 3.4\%, respectively), but not upon exposure to PGV and I34 (0.48\% and $1.45 \%$, respectively).

Complementary, exposure to byproducts did not induce a significant increase in either early or late apoptotic cells with respect to control cells. However, exposure to all 4 byproducts caused significantly higher percentages of necrotic cells (4\% for PGV900, 3.4\% for I31900, 3.3\% for I34900, and 3.4\% for I44900) with respect to control cells (1.2\%). Levels of early apoptotic cells upon exposure to PGV900 (4.7\%) and I31900 (3.1\%) were significantly different from those induced by PGV and I31, respectively. Furthermore, levels of late apoptotic cells upon exposure to I31900 (4.7\%) and I44900 (5.1\%) were significantly different from those induced by I31 and I44, respectively. Finally, levels of necrotic cells were significantly different for PGV900, I31900, and I34900 with respect to their as-received counterparts.

Our results further confirm that the presence and type of organic modifier induces different mechanisms and levels of cell death. For instance, I31 induced a much wider range of cell death, while I44 was shown to only induce significantly higher levels of late apoptosis and necrosis, both relative to controls. These differences again support the hypothesis that mechanism of toxicity depend on the differences in organo-modification of the nanoclays. ${ }^{84}$ Specifically, the modifier for I31 (Figure 1) contains a silane coupling agent used to interact with polymers to a dissimilar 
material such as silica or alumina oxide. ${ }^{85}$ This compound may also cause interaction with biomolecules with inherent hydroxyl groups ${ }^{86}$ or the cell membrane. ${ }^{87}$ Furthermore, the hydroxyl groups located within the organic modifier of I34 have significant potential for bioreactivity. It has been shown for instance that these groups can interact with biomolecules, cause membrane damage, and induce apoptosis. ${ }^{14,88,89}$ Further, both of the organic modifiers in I31 and I44 contained long alkyl chains.

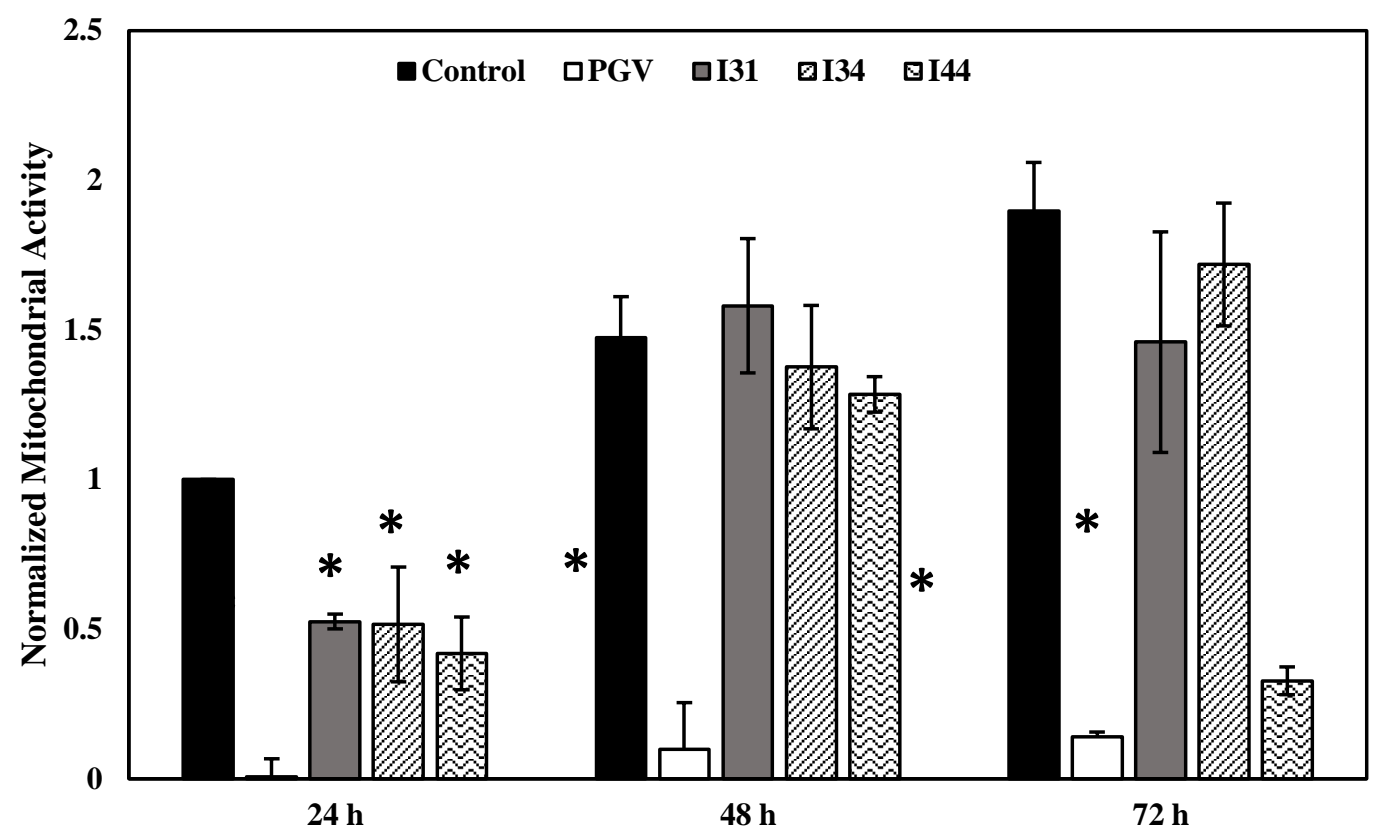

Figure 20. Cellular viability determined with WST-1 assay after 24,48 , and $72 \mathrm{~h}$ exposure, respectively to nanoclays. 
These high-throughput results are support by the changes in cellular metabolic activity before and after exposure to $\mathrm{IC}_{50}$ concentrations of nanoclays or byproducts as supplemented by water-soluble tetrazolium salt (WST-1) assay. Briefly, exposure to PGV led to a significant loss of cellular viability (1\%) with respect to controls (unexposed cells), with slight observed recovery after 48 and $72 \mathrm{~h}$ of observation time (10\% and 13\%, respectively; Figure 20).

Furthermore, cells exposed to I31, I34, and I44 exhibited significantly reduced viability $(52 \%, 51 \%$, and $42 \%$, respectively) after $24 \mathrm{~h}$ of exposure, with respect to controls. After 48 and $72 \mathrm{~h}$ of exposure, however, full recovery of viability (compared to controls) for cells exposed to both I31 and I34 (107\% and 93\%, respectively) was observed. Although cells exposed to I44 recovered viability (87\%) with respect to controls after $48 \mathrm{~h}$ of exposure, a second loss of cellular viability was observed after $72 \mathrm{~h}$ (with samples exhibiting $23 \%$ of control values), indicating a delayed toxic response.

Cells exposed to all 4 thermally degraded byproducts exhibited significant loss of cellular viability at 24 (PGV900 at 36\%, I31900 at 18\%, I34900 at 37\%, and I44900 at 30\%), 48 (46\%, $46 \%, 46 \%$, and $45 \%$, respectively), and $72(38 \%, 29 \%, 34 \%$, and $23 \%$, respectively) h relative to control cells. Only slight recovery of viability cells treated with byproducts, compared to controls, after 48 and $72 \mathrm{~h}$ of exposure was observed. Furthermore, at all 3 time points, viability of cells exposed to PGV900 was significantly higher than those of cells exposed to PGV. Additionally, cellular viability upon exposure to I31900 and I34900 was significantly different than their respective counterparts after 48 and $72 \mathrm{~h}$. Treatment with I44900, however, induced significantly different cellular viability with respect to treatment with I44 at only the $48 \mathrm{~h}$ time point. 
Additionally, exposure to $\mathrm{IC}_{50}$ concentrations of byproducts induced changes in cellular viability (Figure 21).

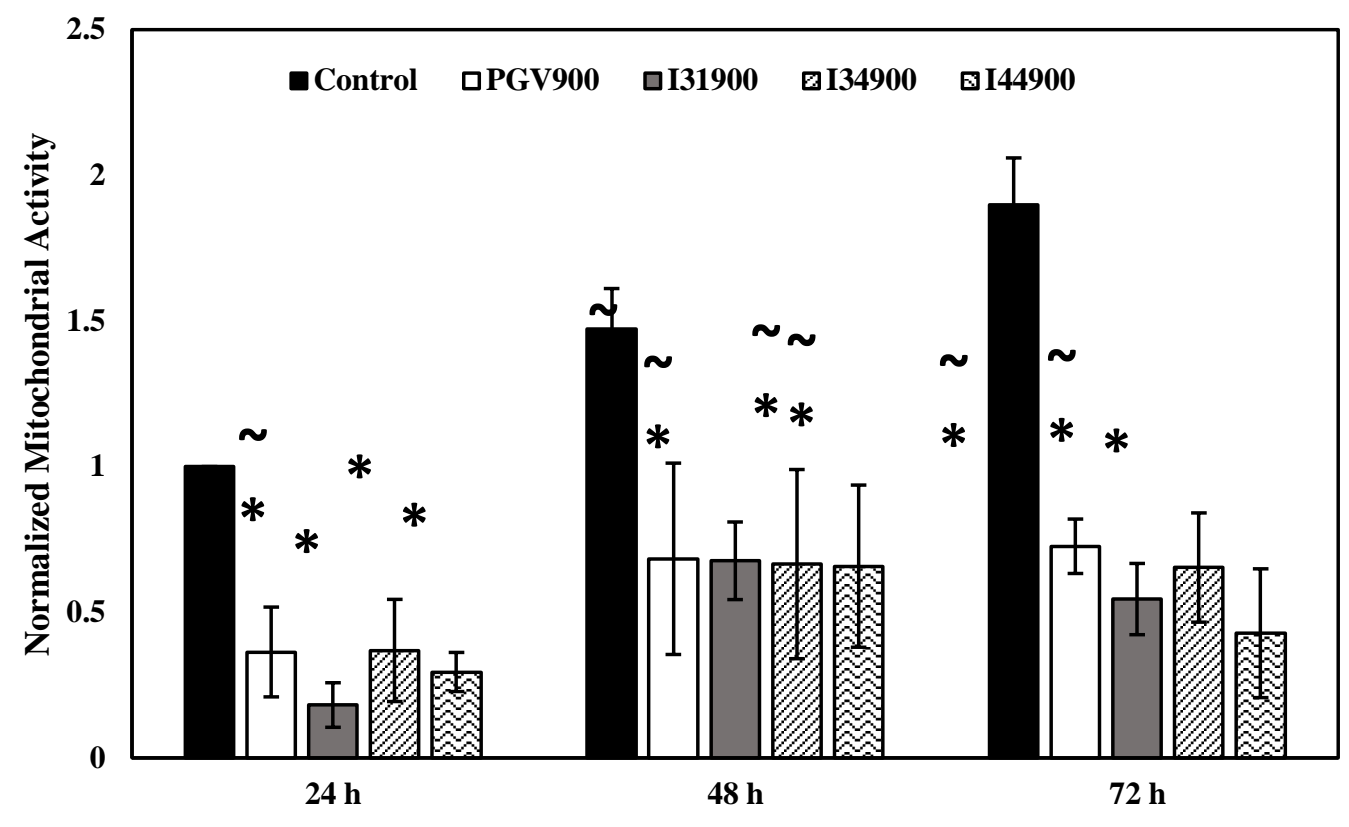

Figure 21. Cellular viability determined with WST-1 assay after 24, 48, and $72 \mathrm{~h}$ exposure, respectively to byproducts.

\section{Proposed mechanisms responsible for differences in cell behavior}

The difference in mechanism of cell death observed for the different exposures may be attributed to the potential of these chains to influence changes in structure of the lipid membrane as well as provoke changes in cell signaling. ${ }^{90}$ Moreover, surface functionalization of nanoparticles with fatty acids has been shown to influence the rate of cellular uptake, presumably due to the interactions with the lipid membrane. ${ }^{91}$ Additionally, we noted that mechanisms of cell death for 
byproducts were similar to one another, but dissimilar from their as-received counterparts. This is again presumably due to loss of the organic modifiers (and their respective bioactivities), silanol groups, and platelet structure. Verma et al., found for instance that platelet-type nanoclays induced greater toxicity on the lung epithelial cell line A549 than tubular-type nanoclays. ${ }^{92}$ Complementary, Zhang et al., found that pyrolytic amorphous silica (comparable to PGV900) induced an ROS-dependent pathway of toxicity in erythrocytes, with eventual hemolysis. ${ }^{93}$ Furthermore, Zhang et al showed that toxicity of amorphous silica was dependent on framework and surface chemistry, triggering differences in inflammation response ${ }^{93}$ with studies by Schreider et al. and Stueckle et al., for instance both reporting that incinerated montmorillonite causes pulmonary inflammation and potentially increases risk for fibrosis development. ${ }^{20,55}$

Previous investigations into nanoclay-induced toxicity have shown that they could activate different cellular responses such as oxidative stress, ${ }^{74,94}$ membrane damage, ${ }^{95}$ mitochondrial dysfunction, ${ }^{95}$ micronucleation, ${ }^{96}$ DNA damage, ${ }^{83,97}$ and apoptosis. ${ }^{74}$ Furthermore, these toxic effects can change given differences in aspect ratio, organo-modification, and agglomeration of the nanoclays. Our observation of significant loss of cellular viability upon exposure to pristine nanoclay corresponds well with knowledge that surface groups such as silanol and aluminum oxide are known to cause inflammation and membrane damage. ${ }^{54,98}$ Additionally, Kondej et al., and Mousseau et al., have recently shown that bentonite and nanoalumina, respectively, both interact with lung surfactant, which may induce change in the manner of particle interaction with lung cells. ${ }^{99,100}$ 
Moreover, we show that cells exposed to I31, I34, and I44 lost 50\% viability (with respect to controls) after $24 \mathrm{~h}$ of exposure, confirming IC50 values. ${ }^{23}$ These results further suggest a difference in mechanism of action compared to pristine nanoclay, indicating significant loss of NADH metabolism (i.e., WST-1 assay), but no loss of monolayer coverage (both HSC and ECIS). Sublethal concentrations of soluble QACs were previously shown to cause mitochondrial fragmentation, inhibition of complex I, and slowed ADP phosphorylation, to result in reduced cellular energy charge in columnar epithelial cells (Inacio et al. 2013). This reduction in cellular energy can induce apoptosis while higher doses induce necrosis or cell lysis (Inacio et al. 2016). Furthermore, within $48 \mathrm{~h}$ of exposure, cells exposed to the tested samples showed viabilities similar to control cells, indicating likely recovery. Note that cells exposed to I44 again lost viability after $72 \mathrm{~h}$ of exposure, indicating a delayed toxic response. This is presumably due to dissolution of the modifier over time. These observations indicate that both presence and type of organic modifier as well as incineration status drive toxicity in vitro. 


\section{Conclusions:}

Our work aimed to provide an assessment of toxicity for a library of nanoclays and their byproducts to help represent the life cycle of these materials. Using high-content screening and real-time, cell-based cytotoxicity assays we showed that exposure of human lung epithelial cells to these nanoclays or byproducts lead to changes in monolayer integrity, cellular behavior and adhesion, to all influence the mechanism of cell death in a manner dependent on physicochemical properties of the individual sample. Specifically, type and presence of organo-modification and incineration status significantly changed surface chemistry and size distribution of the nanoclays and byproducts, which elicited differential cellular response. Future work must focus on elucidating the mechanism of pulmonary toxicity for these nanoparticles using complementary in vitro and in vivo models. A better understanding of the effects of physicochemical properties on toxicity, including immune, airway, and alveolar epithelial cell perturbations could lead to improved prevention by design strategies and enhanced safety practices. 


\section{Notes:}

The findings and conclusions in this article are those of the authors and do not necessarily represent the view of the National Institute for Occupational Safety and Health, Centers for Disease Control and Prevention. Mention of product names does not constitute endorsement.

The authors declare no competing financial interest. 


\section{References:}

1. $\quad$ Markets, F. The Global Market for Graphene; 2017; pp 204-212.

2. McWilliams, A. Nanocomposites, Nanoparticles, Nanoclays, and Nanotubes; 2010; p 144.

3. Markets, F. The global market for nanoclays, 2010-2025; 2015; p 41.

4. Yang, Y.; Westerhoff, P., Presence in, and release of, nanomaterials from consumer products. Adv Exp Med Biol 2014, 811, 1-17.

5. Mackevica, A.; Foss Hansen, S., Release of nanomaterials from solid nanocomposites and consumer exposure assessment - a forward-looking review. Nanotoxicology 2016, $10(6), 641-53$.

6. Debia, M.; Bakhiyi, B.; Ostiguy, C.; Verbeek, J. H.; Brouwer, D. H.; Murashov, V., A Systematic Review of Reported Exposure to Engineered Nanomaterials. Ann Occup Hyg 2016, 60 (8), 916-35.

7. Roes, L.; Patel, M. K.; Worrell, E.; Ludwig, C., Preliminary evaluation of risks related to waste incineration of polymer nanocomposites. Sci Total Environ 2012, 417-418, 76-86.

8. $\quad$ Nowack, B.; Ranville, J. F.; Diamond, S.; Gallego-Urrea, J. A.; Metcalfe, C.; Rose, J.; Horne, N.; Koelmans, A. A.; Klaine, S. J., Potential scenarios for nanomaterial release and subsequent alteration in the environment. Environ Toxicol Chem 2012, 31 (1), 50-9.

9. Mitrano, D. M.; Motellier, S.; Clavaguera, S.; Nowack, B., Review of nanomaterial aging and transformations through the life cycle of nano-enhanced products. Environ Int 2015, 77, 132-47. 
10. SLYZY, Z.; QF, Z.; YJ, D.; YT, S.; MJ, Z., Study on occupational standard of bentonite dust in air of workplace. Chinese Journal of Industrial Hygiene and Occupational Disease 1998, 16, 177-178.

11. Huang, Y.; Zhang, M.; Zou, H.; Li, X.; Xing, M.; Fang, X.; He, J., Genetic damage and lipid peroxidation in workers occupationally exposed to organic bentonite particles. Mutation Research - Genetic Toxicology and Environmental Mutagenesis 2013, 751 (1), 40-44.

12. Holder, A. L.; Vejerano, E. P.; Zhou, X.; Marr, L. C., Nanomaterial disposal by incineration. Environ Sci Process Impacts 2013, 15 (9), 1652-64.

13. Part, F.; Zecha, G.; Causon, T.; Sinner, E. K.; Huber-Humer, M., Current limitations and challenges in nanowaste detection, characterisation and monitoring. Waste Manag 2015, 43, 407-20.

14. Sotiriou, G. A.; Singh, D.; Zhang, F.; Chalbot, M. G.; Spielman-Sun, E.; Hoering, L.; Kavouras, I. G.; Lowry, G. V.; Wohlleben, W.; Demokritou, P., Thermal decomposition of nano-enabled thermoplastics: Possible environmental health and safety implications. J Hazard Mater 2016, 305, 87-95.

15. Buha, J.; Mueller, N.; Nowack, B.; Ulrich, A.; Losert, S.; Wang, J., Physical and chemical characterization of fly ashes from Swiss waste incineration plants and determination of the ash fraction in the nanometer range. Environ Sci Technol 2014, 48 (9), 4765-73.

16. Wagner, A.; White, A. P.; Tang, M. C.; Agarwal, S.; Stueckle, T. A.; Rojanasakul, Y.; Gupta, R. K.; Dinu, C. Z., Incineration of Nanoclay Composites Leads to Byproducts with Reduced Cellular Reactivity. Sci Rep 2018, 8 (1), 10709.

17. Pourchez, J.; Chivas-Joly, C.; Longuet, C.; Leclerc, L.; Sarry, G.; Lopez-Cuesta, J. M., End-of-life incineration of nanocomposites: new insights into nanofiller partitioning into 
by-products and biological outcomes of airborne emission and residual ash. Environmental Science: Nano 2018, 5 (8), 1951-1964.

18. Chivas-Joly, C.; Longuet, C.; Pourchez, J.; Leclerc, L.; Sarry, G.; Lopez-Cuesta, J. M., Physical, morphological and chemical modification of Al-based nanofillers in by-products of incinerated nanocomposites and related biological outcome. Journal of Hazardous Materials 2019, 405-412.

19. Organization, W. H., Bentonite, kaolin and selected clay minerals. World Health Organization: 2015; Vol. 231, p 159.

20. Stueckle, T. A.; Davidson, D. C.; Derk, R.; Kornberg, T. G.; Battelli, L.; Friend, S.; Orandle, M.; Wagner, A.; Dinu, C. Z.; Sierros, K. A.; Agarwal, S.; Gupta, R. K.; Rojanasakul, Y.; Porter, D. W.; Rojanasakul, L., Short-Term Pulmonary Toxicity Assessment of Pre- and Post-incinerated Organomodified Nanoclay in Mice. ACS Nano 2018, 12 (3), 2292-2310.

21. Statistics, U. B. o. L., Nonfatal occupational injuries and illnesses requiring days away from work: 2013. Statistics, U. B. o. L., Ed. 2014.

22. Prevention, C. f. D. C. a., Chronic obstructive pulmonary disease: estimated prevalence by current industry, US working adults aged 18 and over, 2004-2011. 2014.

23. Wagner, A.; White, A. P.; Stueckle, T. A.; Banerjee, D.; Sierros, K. A.; Rojanasakul, Y.; Agarwal, S.; Gupta, R. K.; Dinu, C. Z., Early Assessment and Correlations of Nanoclay's Toxicity to Their Physical and Chemical Properties. ACS Appl Mater Interfaces 2017, 9 (37), 32323-32335.

24. Wagner, A.; Eldawud, R.; White, A.; Agarwal, S.; Stueckle, T. A.; Sierros, K. A.; Rojanasakul, Y.; Gupta, R. K.; Dinu, C. Z., Toxicity evaluations of nanoclays and thermally 
degraded byproducts through spectroscopical and microscopical approaches. Biochim Biophys Acta Gen Subj 2017, 1861 (1 Pt A), 3406-3415.

25. Xiao, C.; Lachance, B.; Sunahara, G.; Luong, J. H., Assessment of cytotoxicity using electric cell-substrate impedance sensing: concentration and time response function approach. Anal Chem 2002, 74 (22), 5748-53.

26. Xiao, C.; Lachance, B.; Sunahara, G.; Luong, J. H., An in-depth analysis of electric cell-substrate impedance sensing to study the attachment and spreading of mammalian cells. Anal Chem 2002, 74 (6), 1333-9.

27. Eldawud, R.; Stueckle, T. A.; Manivannan, S.; Elbaz, H.; Chen, M.; Rojanasakul, Y.; Dinu, C. Z., Real-time analysis of the effects of toxic, therapeutic and sub-therapeutic concentrations of digitoxin on lung cancer cells. Biosens Bioelectron 2014, 59, 192-9.

28. Eldawud, R.; Wagner, A.; Dong, C.; Rojansakul, Y.; Zoica Dinu, C., Electronic platform for real-time multi-parametric analysis of cellular behavior post-exposure to singlewalled carbon nanotubes. Biosens Bioelectron 2015, 71, 269-277.

29. Slater, T. F.; Sawyer, B.; Straeuli, U., Studies on Succinate-Tetrazolium Reductase Systems. Iii. Points of Coupling of Four Different Tetrazolium Salts. Biochim Biophys Acta 1963, 77, 383-93.

30. Yin, L. M.; Wei, Y.; Wang, Y.; Xu, Y. D.; Yang, Y. Q., Long term and standard incubations of WST-1 reagent reflect the same inhibitory trend of cell viability in rat airway smooth muscle cells. Int J Med Sci 2013, 10 (1), 68-72.

31. Geraci, C.; Heidel, D.; Sayes, C.; Hodson, L.; Schulte, P.; Eastlake, A.; Brenner, S., Perspectives on the design of safer nanomaterials and manufacturing processes. J Nanopart Res 2015, 17 (9), 366. 
32. Härkki, O., Biaxially oriented PLA-montmorillonite-nanocomposite for barrier film applications. In Research highlights in industrial biomaterials VTT: Espoo, 2012; Vol. 2, pp $59-62$.

33. Feng, J.; Hao, J.; Du, J.; Yang, R., Effects of organoclay modifiers on the flammability, thermal and mechanical properties of polycarbonate nanocomposites filled with a phosphate and organoclays. Polymer Degradation and Stability 2012, 97 (1), 108-117.

34. Yourdkhani, M.; Mousavand, T.; Chapleau, N.; Hubert, P., Thermal, oxygen barrier and mechanical properties of polylactide-organoclay nanocomposites. Composites Science and Technology 2013, 82, 47-53.

35. Campos-Requena, V. H.; Rivas, B. L.; Pérez, M. A.; Garrido-Miranda, K. A.; Pereira, E. D., Polymer/clay nanocomposite films as active packaging material: Modeling of antimicrobial release. European Polymer Journal 2015, 71, 461-475.

36. Tang, Y.; Lewin, M., Maleated polypropylene OMMT nanocomposite: Annealing, structural changes, exfoliated and migration. Polymer Degradation and Stability 2007, 92 (1), 5360.

37. Wegener, J.; Keese, C. R.; Giaever, I., Electric cell-substrate impedance sensing (ECIS) as a noninvasive means to monitor the kinetics of cell spreading to artificial surfaces. Exp Cell Res 2000, 259 (1), 158-66.

38. Lo, C. M.; Keese, C. R.; Giaever, I., Impedance analysis of MDCK cells measured by electric cell-substrate impedance sensing. Biophys $J$ 1995, 69 (6), 2800-7.

39. Warheit, D. B.; Webb, T. R.; Sayes, C. M.; Colvin, V. L.; Reed, K. L., Pulmonary instillation studies with nanoscale $\mathrm{TiO} 2$ rods and dots in rats: toxicity is not dependent upon particle size and surface area. Toxicol Sci 2006, 91 (1), 227-36. 
40. Nel, A.; Xia, T.; Madler, L.; Li, N., Toxic potential of materials at the nanolevel. Science 2006, 311 (5761), 622-7.

41. Lordan, S.; Higginbotham, C. L., Effect of serum concentration on the cytotoxicity of clay particles. Cell Biol Int 2012, 36 (1), 57-61.

42. Shannahan, J. H.; Brown, J. M.; Chen, R.; Ke, P. C.; Lai, X.; Mitra, S.; Witzmann, F. A., Comparison of nanotube-protein corona composition in cell culture media. Small 2013, 9 (12), 2171-81.

43. Zeinabad, H. A.; Zarrabian, A.; Saboury, A. A.; Alizadeh, A. M.; Falahati, M., Interaction of single and multi wall carbon nanotubes with the biological systems: tau protein and PC12 cells as targets. Sci Rep 2016, 6, 26508.

44. Moore, T. L.; Rodriguez-Lorenzo, L.; Hirsch, V.; Balog, S.; Urban, D.; Jud, C.; Rothen-Rutishauser, B.; Lattuada, M.; Petri-Fink, A., Nanoparticle colloidal stability in cell culture media and impact on cellular interactions. Chem Soc Rev 2015, 44 (17), 6287-305.

45. Braga, V. M.; Del Maschio, A.; Machesky, L.; Dejana, E., Regulation of cadherin function by Rho and Rac: modulation by junction maturation and cellular context. Mol Biol Cell 1999, $10(1), 9-22$.

46. Levesque, J. P.; Simmons, P. J., Cytoskeleton and integrin-mediated adhesion signaling in human CD34+ hemopoietic progenitor cells. Exp Hematol 1999, 27 (4), 579-86.

47. Knights, A. J.; Funnell, A. P.; Crossley, M.; Pearson, R. C., Holding Tight: Cell Junctions and Cancer Spread. Trends Cancer Res 2012, 8, 61-69.

48. Savagner, P., Rise and Fall of Epithelial Phenotype: Concepts of EpithelialMesenchymal Transition. Kluwer Academic/Plenum: 2007; Vol. 248, p 101. 
49. Park, Y. H.; Kim, D.; Dai, J.; Zhang, Z., Human bronchial epithelial BEAS-2B cells, an appropriate in vitro model to study heavy metals induced carcinogenesis. Toxicol Appl Pharmacol 2015, 287 (3), 240-5.

50. Siegrist, K. J.; Reynolds, S. H.; Kashon, M. L.; Lowry, D. T.; Dong, C.; Hubbs, A. F.; Young, S. H.; Salisbury, J. L.; Porter, D. W.; Benkovic, S. A.; McCawley, M.; Keane, M. J.; Mastovich, J. T.; Bunker, K. L.; Cena, L. G.; Sparrow, M. C.; Sturgeon, J. L.; Dinu, C. Z.; Sargent, L. M., Genotoxicity of multi-walled carbon nanotubes at occupationally relevant doses. Part Fibre Toxicol 2014, 11, 6.

51. Gangwal, S.; Brown, J. S.; Wang, A.; Houck, K. A.; Dix, D. J.; Kavlock, R. J.; Hubal, E. A., Informing selection of nanomaterial concentrations for ToxCast in vitro testing based on occupational exposure potential. Environmental health perspectives 2011, 119 (11), 1539-46.

52. Hubbs, A.; Greskevitch, M.; Kuempel, E.; Suarez, F.; Toraason, M., Abrasive blasting agents: designing studies to evaluate relative risk. J Toxicol Environ Health A 2005, 68 (11-12), 999-1016.

53. Kalluri, R., EMT: when epithelial cells decide to become mesenchymal-like cells. J Clin Invest 2009, 119 (6), 1417-9.

54. Pavan, C.; Fubini, B., Unveiling the Variability of "Quartz Hazard" in Light of Recent Toxicological Findings. Chem Res Toxicol 2017, 30 (1), 469-485.

55. Schreider, J. P.; Culbertson, M. R.; Raabe, O. G., Comparative pulmonary fibrogenic potential of selected particles. Environ Res 1985, 38 (2), 256-74.

56. Fruijtier-Polloth, C., The toxicological mode of action and the safety of synthetic amorphous silica-a nanostructured material. Toxicology 2012, 294 (2-3), 61-79. 
57. Perkins, T. N.; Peeters, P. M.; Shukla, A.; Arijs, I.; Dragon, J.; Wouters, E. F.; Reynaert, N. L.; Mossman, B. T., Indications for distinct pathogenic mechanisms of asbestos and silica through gene expression profiling of the response of lung epithelial cells. Hum Mol Genet 2015, 24 (5), 1374-89.

58. Perkins, T. N.; Dentener, M. A.; Stassen, F. R.; Rohde, G. G.; Mossman, B. T.; Wouters, E. F.; Reynaert, N. L., Alteration of canonical and non-canonical WNT-signaling by crystalline silica in human lung epithelial cells. Toxicol Appl Pharmacol 2016, 301, 61-70.

59. Longhin, E.; Holme, J. A.; Gutzkow, K. B.; Arlt, V. M.; Kucab, J. E.; Camatini, M.; Gualtieri, M., Cell cycle alterations induced by urban PM2.5 in bronchial epithelial cells: characterization of the process and possible mechanisms involved. Part Fibre Toxicol 2013, 10, 63.

60. Wu, J.; Shi, Y.; Asweto, C. O.; Feng, L.; Yang, X.; Zhang, Y.; Hu, H.; Duan, J.; Sun, Z., Fine particle matters induce DNA damage and G2/M cell cycle arrest in human bronchial epithelial BEAS-2B cells. Environmental science and pollution research international 2017, 24 (32), 25071-25081.

61. Loxham, M.; Morgan-Walsh, R. J.; Cooper, M. J.; Blume, C.; Swindle, E. J.; Dennison, P. W.; Howarth, P. H.; Cassee, F. R.; Teagle, D. A.; Palmer, M. R.; Davies, D. E., The effects on bronchial epithelial mucociliary cultures of coarse, fine, and ultrafine particulate matter from an underground railway station. Toxicol Sci 2015, 145 (1), 98-107.

62. Giaever, I.; Keese, C. R., Micromotion of mammalian cells measured electrically. Proc Natl Acad Sci U S A 1991, 88 (17), 7896-900. 
63. Eldawud, R.; Reitzig, M.; Opitz, J.; Rojansakul, Y.; Jiang, W.; Nangia, S.; Dinu, C. Z., Combinatorial approaches to evaluate nanodiamond uptake and induced cellular fate. Nanotechnology 2016, 27 (8), 085107.

64. Re, F.; Zanetti, A.; Sironi, M.; Polentarutti, N.; Lanfrancone, L.; Dejana, E.; Colotta, F., Inhibition of anchorage-dependent cell spreading triggers apoptosis in cultured human endothelial cells. The Journal of cell biology 1994, 127 (2), 537-46.

65. Hussain, S.; Thomassen, L. C.; Ferecatu, I.; Borot, M. C.; Andreau, K.; Martens, J. A.; Fleury, J.; Baeza-Squiban, A.; Marano, F.; Boland, S., Carbon black and titanium dioxide nanoparticles elicit distinct apoptotic pathways in bronchial epithelial cells. Part Fibre Toxicol 2010, 7, 10 .

66. Yamada, K. M.; Geiger, B., Molecular interactions in cell adhesion complexes. Curr Opin Cell Biol 1997, 9 (1), 76-85.

67. Song, M.; Zeng, L.; Yuan, S.; Yin, J.; Wang, H.; Jiang, G., Study of cytotoxic effects of single-walled carbon nanotubes functionalized with different chemical groups on human MCF7 cells. Chemosphere 2013, 92 (5), 576-82.

68. Dong, C.; Campell, A. S.; Eldawud, R.; Perhinschi, G.; Rojanasakul, Y.; Dinu, C. Z., Effects of acid treatment on structure, properties and biocompatibility of carbon nanotubes. Applied Surface Science 2013, 264, 261-268.

69. Dong, C.; R, E. I.; Sargent, L. M.; Kashon, M. L.; Lowry, D.; Rojanasakul, Y.; Dinu, C. Z., Towards Elucidating the Effects of Purified MWCNTs on Human Lung Epithelial cells. Environ Sci Nano 2014, 1 (6), 95-603. 
70. Wang, L.; Wang, L.; Yin, H.; Xing, W.; Yu, Z.; Guo, M.; Cheng, J., Real-time, label-free monitoring of the cell cycle with a cellular impedance sensing chip. Biosens Bioelectron 2010, 25 (5), 990-5.

71. Xiao, C.; Luong, J. H., Assessment of cytotoxicity by emerging impedance spectroscopy. Toxicol Appl Pharmacol 2005, 206 (2), 102-12.

72. Male, K. B.; Lachance, B.; Hrapovic, S.; Sunahara, G.; Luong, J. H., Assessment of cytotoxicity of quantum dots and gold nanoparticles using cell-based impedance spectroscopy. Anal Chem 2008, 80 (14), 5487-93.

73. Storm, G.; Belliot, S. O.; Daemen, T.; Lasic, D. D., Surface modification of nanoparticles to oppose uptake by the mononuclear phagocyte system. Advanced Drug Delivery Reviews 1995, 17 (1), 31-48.

74. Baek, M.; Kim, I. S.; Yu, J.; Chung, H. E.; Choy, J. H.; Choi, S. J., Effect of different forms of anionic nanoclays on cytotoxicity. J Nanosci Nanotechnol 2011, 11 (2), 18036.

75. Lu, F.; Wu, S. H.; Hung, Y.; Mou, C. Y., Size effect on cell uptake in wellsuspended, uniform mesoporous silica nanoparticles. Small 2009, 5 (12), 1408-13.

76. Roy, I.; Ohulchanskyy, T. Y.; Bharali, D. J.; Pudavar, H. E.; Mistretta, R. A.; Kaur, N.; Prasad, P. N., Optical tracking of organically modified silica nanoparticles as DNA carriers: a nonviral, nanomedicine approach for gene delivery. Proc Natl Acad Sci U S A 2005, 102 (2), 279-84.

77. Stearns, R. C.; Paulauskis, J. D.; Godleski, J. J., Endocytosis of ultrafine particles by A549 cells. Am J Respir Cell Mol Biol 2001, 24 (2), 108-15. 
78. Herd, H.; Daum, N.; Jones, A. T.; Huwer, H.; Ghandehari, H.; Lehr, C. M., Nanoparticle geometry and surface orientation influence mode of cellular uptake. ACS Nano 2013, 7 (3), 1961-73.

79. Slowing, I.; Trewyn, B. G.; Lin, V. S., Effect of surface functionalization of MCM41-type mesoporous silica nanoparticles on the endocytosis by human cancer cells. J Am Chem Soc 2006, 128 (46), 14792-3.

80. Dong, C.; Kashon, M. L.; Lowry, D.; Dordick, J. S.; Reynolds, S. H.; Rojanasakul, Y.; Sargent, L. M.; Dinu, C. Z., Exposure to carbon nanotubes leads to changes in the cellular biomechanics. Advanced healthcare materials 2013, 2 (7), 945-51.

81. Kim, J. A.; Aberg, C.; Salvati, A.; Dawson, K. A., Role of cell cycle on the cellular uptake and dilution of nanoparticles in a cell population. Nat Nanotechnol 2011, 7 (1), 62-8.

82. Yoshida, T.; Yoshioka, Y.; Matsuyama, K.; Nakazato, Y.; Tochigi, S.; Hirai, T.; Kondoh, S.; Nagano, K.; Abe, Y.; Kamada, H.; Tsunoda, S.; Nabeshi, H.; Yoshikawa, T.; Tsutsumi, Y., Surface modification of amorphous nanosilica particles suppresses nanosilicainduced cytotoxicity, ROS generation, and DNA damage in various mammalian cells. Biochem Biophys Res Commun 2012, 427 (4), 748-52.

83. Sharma, A. K.; Schmidt, B.; Frandsen, H.; Jacobsen, N. R.; Larsen, E. H.; Binderup, M. L., Genotoxicity of unmodified and organo-modified montmorillonite. Mutat Res 2010, $700(1-2), 18-25$.

84. Janer, G.; Fernandez-Rosas, E.; Mas del Molino, E.; Gonzalez-Galvez, D.; Vilar, G.; Lopez-Iglesias, C.; Ermini, V.; Vazquez-Campos, S., In vitro toxicity of functionalised nanoclays is mainly driven by the presence of organic modifiers. Nanotoxicology 2014, 8 (3), 27994. 
85. Sterman, S.; Marsden, J. G., Silane coupling agents. Industrial and Engineering Chemistry 1966, 58 (3), 33-37.

86. Soteropulos, C. E.; Hunt, H. K., Attaching biological probes to silica optical biosensors using silane coupling agents. Journal of Visualized Experiments 2012, (63).

87. Ojea-Jiménez, I.; Urbán, P.; Barahona, F.; Pedroni, M.; Capomaccio, R.; Ceccone, G.; Kinsner-Ovaskainen, A.; Rossi, F.; Gilliland, D., Highly Flexible Platform for Tuning Surface Properties of Silica Nanoparticles and Monitoring Their Biological Interaction. ACS Applied Materials and Interfaces 2016, 8 (7), 4838-4850.

88. Tarn, D.; Ashley, C. E.; Xue, M.; Carnes, E. C.; Zink, J. I.; Brinker, C. J., Mesoporous silica nanoparticle nanocarriers: biofunctionality and biocompatibility. Acc Chem Res 2013, 46 (3), 792-801.

89. Das, S.; Singh, S.; Singh, V.; Joung, D.; Dowding, J. M.; Reid, D.; Anderson, J.; Zhai, L.; Khondaker, S. I.; Self, W. T.; Seal, S., Oxygenated functional group density on graphene oxide: Its effect on cell toxicity. Particle and Particle Systems Characterization 2013, $30(2), 148-157$.

90. Ibarguren, M.; Lopez, D. J.; Escriba, P. V., The effect of natural and synthetic fatty acids on membrane structure, microdomain organization, cellular functions and human health. Biochim Biophys Acta 2014, 1838 (6), 1518-28.

91. Meczynska-Wielgosz, S.; Piotrowska, A.; Majkowska-Pilip, A.; Bilewicz, A.; Kruszewski, M., Effect of Surface Functionalization on the Cellular Uptake and Toxicity of Nanozeolite A. Nanoscale Res Lett 2016, 11 (1), 123. 
92. Verma, N. K.; Moore, E.; Blau, W.; Volkov, Y.; Babu, P. R., Cytotoxicity evaluation of nanoclays in human epithelial cell line A549 using high content screening and realtime impedance analysis. Journal of Nanoparticle Research 2012, 14 (9).

93. Zhang, H.; Dunphy, D. R.; Jiang, X.; Meng, H.; Sun, B.; Tarn, D.; Xue, M.; Wang, X.; Lin, S.; Ji, Z.; Li, R.; Garcia, F. L.; Yang, J.; Kirk, M. L.; Xia, T.; Zink, J. I.; Nel, A.; Brinker, C. J., Processing pathway dependence of amorphous silica nanoparticle toxicity: colloidal vs pyrolytic. J Am Chem Soc 2012, 134 (38), 15790-804.

94. Maisanaba, S.; Pichardo, S.; Puerto, M.; Gutierrez-Praena, D.; Camean, A. M.; Jos, A., Toxicological evaluation of clay minerals and derived nanocomposites: a review. Environ Res 2015, 138, 233-54.

95. Han, H. K.; Lee, Y. C.; Lee, M. Y.; Patil, A. J.; Shin, H. J., Magnesium and calcium organophyllosilicates: synthesis and in vitro cytotoxicity study. ACS Appl Mater Interfaces 2011, 3 (7), 2564-72.

96. Zhao, F.; Zhao, Y.; Liu, Y.; Chang, X.; Chen, C.; Zhao, Y., Cellular uptake, intracellular trafficking, and cytotoxicity of nanomaterials. Small 2011, 7 (10), 1322-37.

97. Houtman, J.; Maisanaba, S.; Puerto, M.; Gutiérrez-Praena, D.; Jordá, M.; Aucejo, S.; Jos, A., Toxicity assessment of organomodified clays used in food contact materials on human target cell lines. Applied Clay Science 2014, 90, 150-158.

98. Willhite, C. C.; Karyakina, N. A.; Yokel, R. A.; Yenugadhati, N.; Wisniewski, T. M.; Arnold, I. M.; Momoli, F.; Krewski, D., Systematic review of potential health risks posed by pharmaceutical, occupational and consumer exposures to metallic and nanoscale aluminum, aluminum oxides, aluminum hydroxide and its soluble salts. Crit Rev Toxicol 2014, 44 Suppl 4, 180. 
99. Kondej, D.; Sosnowski, T. R., Alteration of biophysical activity of pulmonary surfactant by aluminosilicate nanoparticles. Inhal Toxicol 2013, 25 (2), 77-83.

100. Mousseau, F.; Le Borgne, R.; Seyrek, E.; Berret, J. F., Biophysicochemical Interaction of a Clinical Pulmonary Surfactant with Nanoalumina. Langmuir 2015, 31 (26), 734654. 


\section{Appendices:}

1. Article: Stueckle, T.*, White, A.*, Wagner, A., Gupta, R., Rojanasakul, Y., Dinu, C.Z., "Impacts of Organomodified Nanoclays and their Incinerated Byproducts on Bronchial Cell Monolayer Integrity", Chemical Research in Toxicology (2019) 32, 12, 2445-2458 (*Authors contributed equally).

2. Supporting information: Stueckle, T.*, White, A.*, Wagner, A., Gupta, R., Rojanasakul, Y., Dinu, C.Z., "Impacts of Organomodified Nanoclays and their Incinerated Byproducts on Bronchial Cell Monolayer Integrity", Chemical Research in Toxicology (2019) 32, 12, 2445-2458 (*Authors contributed equally) 